\title{
THE FUTURE OF NATURAL GAS IN CHINA: EFFECTS OF PRICING REFORM AND CLIMATE POLICY
}

\author{
DANWEI ZHANG and SERGEY PALTSEV* \\ MIT Joint Program on the Science and Policy of Global Change \\ Massachusetts Institute of Technology, Cambridge, MA, USA \\ "paltsev@mit.edu
}

Accepted 31 August 2016

Published 10 November 2016

\begin{abstract}
China is currently attempting to reduce greenhouse gas emissions and increase natural gas consumption as a part of broader national strategies to reduce the air pollution impacts of the nation's energy system. To assess the scenarios of natural gas development up to 2050, we employ a global energy-economic model - the MIT Economic Projection and Policy Analysis (EPPA) model. The results show that a cap-and-trade policy will enable China to achieve its climate mitigation goals, but will also reduce natural gas consumption. An integrated policy that uses a part of the carbon revenue obtained from the cap-and-trade system to subsidize natural gas use promotes natural gas consumption, resulting in a further reduction in coal use relative to the cap-and-trade policy case. The integrated policy has a very moderate welfare cost; however, it reduces air pollution and allows China to achieve both the climate objective and the natural gas promotion objective.
\end{abstract}

Keywords: Natural gas; China; climate policy; pricing reform; economic modeling.

\section{Introduction}

China's energy supply has long been dominated by coal. China has already become the world's largest $\mathrm{CO}_{2}$ emitter and suffers enormously from air pollution (He et al., 2002; Matus et al., 2012; Kan et al., 2012). Over the past three decades, about two-thirds of China's primary energy consumption has come from coal, causing significant local, regional and global environmental pollution. Natural gas use generates much less pollution than coal (EPA, 1995; EIA, 1999; Cai et al., 2012), and natural gas is often regarded as a cleaner energy. Thus, substitution of natural gas for coal has been listed by the Chinese government as an important part of China's sustainable energy system transformation strategy. At present, natural gas accounts for approximately $6 \%$ of China's primary energy supply, which is substantially below the global average of $24 \%$ (BP, 2015). According to China's national energy strategy action plan, the share of

This is an Open Access article published by World Scientific Publishing Company. It is distributed under the terms of the Creative Commons Attribution 4.0 (CC-BY) License. Further distribution of this work is permitted, provided the original work is properly cited. 
natural gas in primary energy supply should reach $10 \%$ by 2020 (State Council of China, 2014). Natural gas has a great potential for expansion in China's future energy market, and natural gas use is widely encouraged in Chinese cities as an important option to address deteriorated air quality and improve living standards. However, there are still significant economic and institutional barriers to expansion of natural gas consumption. The natural gas future in China is quite uncertain without innovative approaches to address these barriers.

Pricing is one of the most important mechanisms in the future of natural gas development. Per unit of energy, natural gas price is substantially higher than the coal price in China, and the large-scale substitution of natural gas for coal requires a policy support. Natural gas prices in China have long been determined by government agencies, predominately by the National Development and Reform Commission (NDRC), with limited flexibility, predictability and transparency (Paltsev and Zhang, 2015a). There is also a significant research literature that finds that public interventions will be needed to enable China's transition to a low carbon energy economy (Chai and Zhang, 2010; Zhou et al., 2014; Wang and Cheng, 2015; Zhang et al., 2016). Of the proposed public policies, a carbon tax or carbon dioxide emissions cap-and-trade scheme are commonly considered as a cost effective approach in mitigation (Paltsev et al., 2012; Zhang et al., 2016). China recently announced its plans to build a national carbon emission cap-and-trade system (The White House, 2015), and in its intended nationally determined contribution (INDC) submitted to the United Nations in December 2015 (NDRC, 2015), China also pledged to peak its $\mathrm{CO}_{2}$ emissions around 2030 by introducing a number of policy measures highlighting the cap-and-trade system. Some studies have analyzed the level of the carbon price needed for China to achieve its climate pledge (Zhang et al., 2016). However, as natural gas contains carbon, the natural gas use could be penalized by the carbon price. The existing studies do not address the issue to what extent such a carbon price will affect China's natural gas consumption. Such investigation, however, is important as climate policy might lead to a substantial deviation from the natural gas promotion objective.

Our goal is to examine the consistency of China's climate policy with the natural gas promotion objective, and to assess an integrated policy approach which combines a natural gas subsidy scheme with a cap-and-trade policy. We investigate a policy instrument and quantify a magnitude of the required policy support that allows achieving both the climate mitigation objective and natural gas promotion objective, establishing conditions where both objectives can be simultaneously achieved. We simulate natural gas price trajectories under both oil-linked and market-determined pricing schemes to examine the difference between the two pricing mechanisms. We also evaluate the changes in sectoral use of natural gas and costs to the economy from alternative policy instruments.

These projections are based on the energy-economic model developed at the MIT Joint Program on the Science and Policy of Global Change: the MIT Economic Projection and Policy Analysis (EPPA) model (Paltsev et al., 2005; Chen et al., 2015). 
An advantage of this modeling framework is that both the commodities' quantities and prices are endogenously determined. For this study, we enhanced the EPPA model with a representation of China's latest policy objectives and updated the technology costs in China's power generation sector.

\section{Policies Affecting Natural Gas Supply and Demand}

\subsection{Natural gas pricing policy}

Natural gas pricing reform has played a vital role in promoting natural gas supply from both domestic and overseas sources (Paltsev and Zhang, 2015a). China's natural gas pricing used to favor consumers. The highly regulated pricing regime resulted in a low gas price and failed to provide enough incentives for natural gas suppliers. A new gas pricing reform was first put into trial in Guangdong and Guangxi provinces in December 2011, and was introduced nationwide in July 2013. The pricing reform aims to create a more market-based pricing mechanism to encourage natural gas supply. To minimize potential political opposition during the initial stages of the reform, the government adopted a two-tier pricing approach for the period of transition. The transitional process lasted until April 2015. During the transitional process, the pricing for the incremental volume of natural gas supply was linked to international oil product prices, while the prices for the existing volume was gradually increased to the levels of the incremental volume. Now, China's wholesale natural gas price is connected to a weighted price of international fuel oil and liquid petroleum gas (LPG) prices. The oillinked pricing regime is more predictable and transparent compared to the old highly regulated pricing system where prices were established arbitrarily and changed unpredictably.

\subsection{Other natural gas promotion policy}

In addition to the pricing reform, the Chinese government implements a set of natural gas promotion policies. The primary objective of China's natural gas promotion policy is to facilitate the substitution of natural gas for coal to address the air pollution problems and improve the household quality of life in Chinese cities. Burning coal emits air pollutants such as $\mathrm{SO}_{2}, \mathrm{NO}_{x}$, black carbon and fine particles such as $\mathrm{PM}_{2.5}$ and others. China's air pollution is largely attributed to the massive use of coal and a lack of clean coal technologies.

According to a study based on hourly data for China (Rohde and Muller, 2015), airborne particulate matter (PM) with a size less than 2.5 microns $\left(\mathrm{PM}_{2.5}\right)$ has the highest levels $\left(52 \mu \mathrm{g} / \mathrm{m}^{3}\right)$ above the "healthy" standards for air pollution $\left(12 \mu \mathrm{g} / \mathrm{m}^{3}\right)$ established by US EPA (EPA, 2014). Geographically, the highest intensity is in the area between Beijing and Shanghai. Patterns for PM with a size less than 10 microns $\left(\mathrm{PM}_{10}\right)$, sulfur dioxide $\left(\mathrm{SO}_{2}\right)$ and nitrogen dioxide $\left(\mathrm{NO}_{2}\right)$ are similar but less severe. The major source of air pollution is attributed to fossil fuel burning in power plants, 
especially in coal power plants. Industrial facilities and transportation fuels also contribute to air pollution (Rohde and Muller, 2015). It is estimated that air pollution is killing about 4400 people in China every single day (or 1.6 million a year) (Rohde and Muller, 2015). Another study estimates that air pollution contributes to 1.2 million of deaths per year in China (Yang et al., 2013). Natural gas is regarded as cleaner than coal fossil fuel because it creates less air pollution than coal during the combustion process. Compared to coal, natural gas produces 150 to 400 times less PM for the same energy delivered (EIA, 1999; Cai et al., 2012). In this regard the Chinese central government and local governments often attach a great value to an increase in a share of natural gas in the energy supply mix.

China's natural gas promotion policies include national and urban targets for natural gas use; regulations on natural utilizations; natural gas pricing; and subsidies, tax relief and feed-in tariffs for natural gas fired electricity generations. China's NationalEnergy Development Strategy Action Plan (2014-2020) emphasizes the role of natural gas in China's energy system transformation and sets a goal for the share of natural gas in China's primary energy supply to exceed $10 \%$ by 2020 (State Council of China, 2014). Chinese government has also set restrictions for natural gas use. According to the Revised Natural Gas Utilization Policy (NDRC, 2012), natural gas is encouraged for consumption as fuel in residential, manufacturing, electricity and transportation sectors, but is discouraged as a feedstock in producing chemicals.

In China, one policy instrument for promoting natural gas use is the import valueadded tax refund to encourage natural gas imports (MOF, 2011). Others include the feed-in tariffs for gas-fired power plants to encourage substitution of natural gas for coal in the electricity sector (NDRC, 2014). Since 2007, coal-bed methane producers receive a subsidy of 0.2 yuan (¥) per cubic meter if the gas is delivered to residential and industrial users (MOF, 2007). While these instruments promote natural gas use, they can create economic distortions. In the modeling exercise described later, a general subsidy is used as a proxy for these policy instruments.

\subsection{Climate-related policy}

In 2015, the Chinese government submitted to the United Nations its climate action plan (NDRC, 2015). According to the plan, China is pledged to peak its $\mathrm{CO}_{2}$ emissions around 2030 and decrease carbon intensity $\left(\mathrm{CO}_{2}\right.$ emissions per unit of GDP) by 60-65\% below 2005 levels by the same year. The new carbon intensity target builds on China's existing target, from the Copenhagen climate talks in 2009 - to reduce its $\mathrm{CO}_{2}$ intensity by $40-45 \%$ in 2020, relative to 2005 levels (NRDC, 2015). As a major policy instrument to honor the pledges listed in its INDC, China has recently decided to establish a nationwide carbon dioxide emissions cap-and-trade system, or emission trading scheme (ETS). Chinese President Xi Jinping officially announced that a nationwide ETS will be launched in 2017 (The White House, 2015). 


\section{The EPPA Model and Its Modification}

\subsection{Brief introduction to the EPPA model}

To assess China's natural gas development scenarios, we use the MIT EPPA model (Paltsev et al., 2005; Chen et al., 2015), which is a multi-region, multi-sector dynamic model of the global economy. It has been widely applied to the impact evaluation of climate and energy policies on economic and energy systems for global and regional studies. As a computable general equilibrium model, the EPPA model projects the interactions among production sectors and between the producers and consumers influenced by commodity and resource prices. The EPPA model can provide an examination of the economy-wide effects of different policies, and incorporates numerous technologies to provide details about the resulting technology mix for different policy approaches. As a global framework, the EPPA model can also be used to assess policy effects on international trade and on global emissions mitigation.

EPPA represents the global economy with China as a separate region of the model. The GTAP data set (Narayanan et al., 2012) provides the base year (2007) information on the input-output structure for regional economies, including bilateral trade flows. The GTAP data are aggregated into 18 regions and 24 sectors. Figure 1 shows the geographical regions represented explicitly in the model.

EPPA explicitly represents interactions among sectors (through inter-industry inputs) and regions (via bilateral trade flows). It simulates production in each region at the sectoral level. Sectoral output is produced from primary factors including multiple categories of depletable and renewable natural capital, produced capital and labor

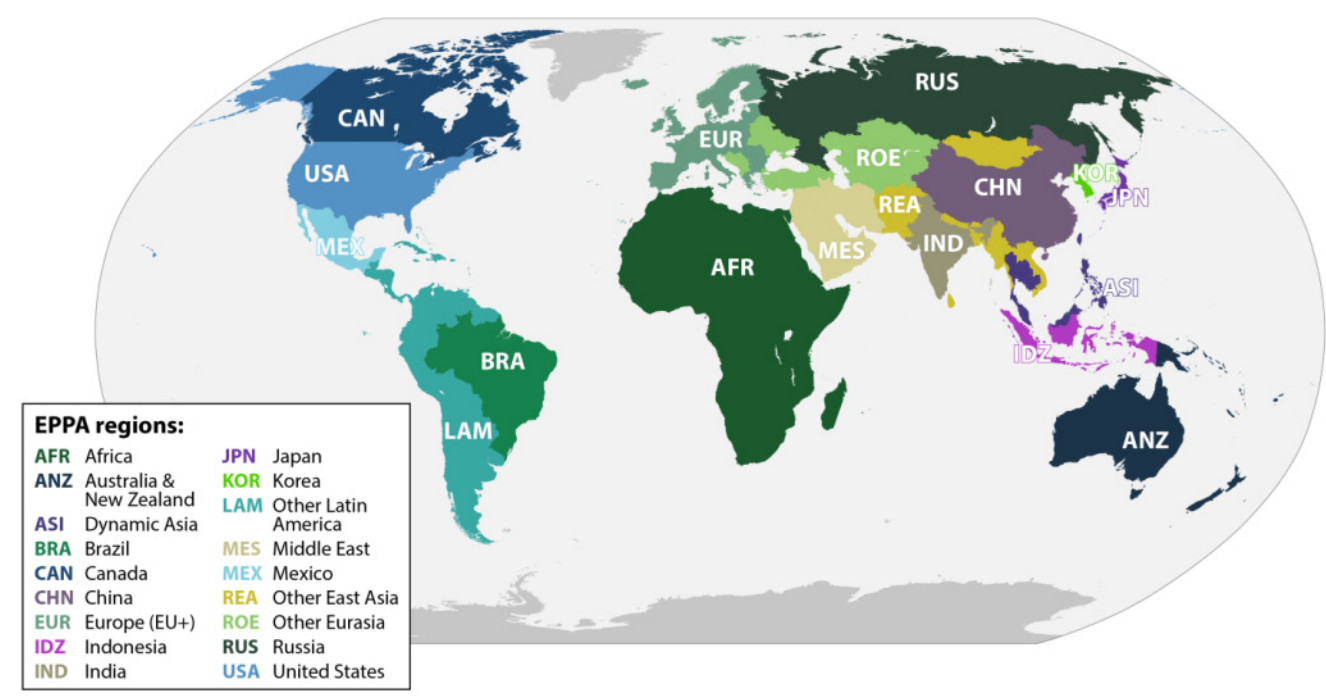

Source: Adopted from MIT Joint Program (2014) and Chen et al. (2015).

Figure 1. Regions in the EPPA model. 
Table 1. Sectors and factor inputs in the EPPA model.

\begin{tabular}{lll}
\hline \multicolumn{1}{c}{ Sector } & & \multicolumn{1}{c}{ Primary factor inputs } \\
\hline Production sectors & & \multicolumn{1}{c}{ Depletable natural capital } \\
Agriculture - Crops & CROP & Conventional Oil Resources \\
Agriculture - Livestock & LIVE & Shale Oil \\
Agriculture - Forestry & FORS & Conventional Gas Resources \\
Food Products & FOOD & Unconventional Gas Resources \\
Coal & COAL & Uranium Resources \\
Crude Oil & OIL & Coal Resources \\
Refined Oil & ROIL & Renewable Natural Capital \\
Natural Gas & GAS & Solar Resources \\
Electricity & ELEC & Wind Resources \\
Energy-Intensive Industries & EINT & Hydro Resources \\
Other Industries & OTHR & Land \\
Services & SERV & Produced Capital \\
Transport & TRAN & Conventional Capital (Bldgs \& Mach.) \\
Household Sectors & & Labor \\
Household Transport & HHTRAN & \\
Ownership of Dwellings & DWE & \\
Other Household Consumption & \\
\hline
\end{tabular}

\footnotetext{
${ }^{a}$ Natural Gas production includes production from conventional resources, shale gas, tight gas, coal-bed methane and coal gasification.

${ }^{b}$ Electricity production technologies include coal, natural gas, oil, advanced natural gas, advanced coal, hydro, nuclear, biomass, wind, solar, wind with natural gas backup, wind with biomass backup, advanced coal with carbon capture and storage, advanced natural gas with carbon capture and storage and advanced nuclear.

${ }^{\mathrm{c}}$ Other Household Consumption is resolved at the production sectors level.

Source: Adopted from Chen et al. (2015).
}

(Table 1). Intermediate inputs to sectoral production are represented through a complete input-output structure.

The EPPA model projects $\mathrm{CO}_{2}$ emissions and other greenhouse gases (GHGs) such as methane, nitrous oxide, hydrofluorocarbons, perfluorocarbons and sulfur hexafluoride. The model also projects pollution emissions from sulfates, nitrogen oxides, black carbon, organic carbon, carbon monoxide, ammonia and nonmethane volatile organic compounds. The data on air pollutants are based on the HTAP2.1 database (HTAP, 2013). Mitigation options are also reprensented in the model.

The dynamics in the EPPA model are driven by endogenously determined capital accumulation resulting from savings and investments as well as exogenously determined factors including labor force growth, resource availability and the rate of technological change (e.g., explicit advanced technologies and productivity improvement in labor, land and energy) (Chen et al., 2015). GDP and income growth drives up demand for goods produced from each sector (Octaviano et al., 2016). Fossil fuel production costs increase as fossil fuel resources deplete. Increasing the use of 
Table 2. Backstop technologies.

\begin{tabular}{lc}
\hline Backstop technology & EPPA6 \\
\hline First generation biofuels & bio-fg \\
Second generation biofuels & bio-oil \\
Oil shale & synf-oil \\
Synthetic gas from coal & synf-gas \\
Hydrogen & h2 \\
Advanced nuclear & adv-nucl \\
Integrated Gasification Combined Cycle with CCS & Igcap \\
Natural Gas Combined Cycle & Ngcc \\
Natural Gas Combined Cycle with CCS & Ngcap \\
Wind generation & Wind \\
Bio-electricity & Bioelec \\
Wind power combined with bio-electricity & Windbio \\
Wind power combined with gas-fired power & Windgas \\
Solar generation & Solar \\
\hline
\end{tabular}

Source: Chen et al. (2015).

advanced technologies (including energy from renewable sources) leads to learningby-doing and a reduction in scarcity rents (associated with shortages in skilled labor and monopoly rents). With increasing prices of fossil fuel and reduced costs of advanced technologies, the new technologies can become competitive with the existing technologies relying on fossil fuels (Morris et al., 2014). These features enable the EPPA model to simulate a dynamic evolution of technology mixes for different energy and climate-related policies.

Based on engineering data, EPPA includes advanced technologies that are not widely deployed but have a large application potential in the future, namely "backstop technologies" as shown in Table 2 (Chen et al., 2015). These technologies are usually more expensive than the conventional technologies in the base year, but they may become cost efficient with technology improvement and favorable policies. The model has calibrated the output of these backstop technologies for historical years (2007 and 2010) based on the information from the World Energy Outlook from the International Energy Agency (IEA, 2012).

\subsection{Representing characteristics of China's energy sector in the EPPA model}

Like production for other commodities, advanced technologies in the EPPA model are represented by nested constant elasticity of substitution (CES) production functions. Key features of advanced technology representation include resource inputs and the depiction of transition costs for scaling up production, which is expressed as a markup relative to the price of pulverized coal technology in 2010. Based on a detailed survey of local information from the latest publications, including government statistics on capital cost, government announcements on fuel cost, and project-based peer-reviewed 
studies, we updated the assumptions for capital cost, fixed operation and maintenance (O\&M) cost, variable O\&M cost and fuel cost of each advanced technology in China. Information on production cost and input structure of existing and advanced technologies in China is presented in Table 3.

Currently, the coal price in China ranges from 310 to $¥ 445 /$ ton depending on heating values (CQCOAL, 2015). For the analysis here, we use the coal price of $¥ 400$ / ton for coal with a thermal value of $5500 \mathrm{kcal} / \mathrm{kg}$. The capital cost for a pulverized coal-fired power plant is estimated to be about $¥ 3680 / \mathrm{kW}^{1}$ (NEA, 2014). The variable O\&M cost and fixed O\&M cost are assumed at $¥ 0.037 / \mathrm{kWh}$ and $¥ 62 / \mathrm{kW}$, respectively, according to Huang (2012). The levelized cost of pulverized coal technology is calculated to be around $¥ 0.28 / \mathrm{kWh}$ or US $\$ 41.93 / \mathrm{MWh}$ with a discount rate of $8.5 \%$.

The levelized cost of natural gas combined cycle (NGCC) in China is calculated to be at US\$73.61/MWh, which is about $75 \%$ higher than the cost for pulverized coalfired technology. We base our calculation on the reported capital cost for NGCC power plant in Jiangsu, which is around $¥ 3330 / \mathrm{kWh}$ (Sun and Ning, 2014). The variable O\&M and fixed O\&M costs are estimated to be $¥ 0.014 / \mathrm{kWh}$ and $¥ 98 / \mathrm{kW}$, respectively. We also use the actual reported capacity factor for thermal plants from China Electricity Council (2015). We use the power sector natural gas price in Shanghai to calculate the fuel cost for NGCC. Currently, the natural gas price for power sector in Shanghai is $¥ 2.5 / \mathrm{m}^{3}$ (SHDRC, 2015), which is about $¥ 60.46 / \mathrm{MMBtu}$ assuming that 1000 cubic meter natural gas contents 35.7 MMBtu (BP, 2014). Natural gas prices for power sector vary across regions. There are several considerations for the reason that we use natural gas price in Shanghai in our calculations. Firstly, this largely reflects the natural gas prices used by NGCC plants in China as most of the NGCC power plants are located in the east of China in places such as Beijing, Shanghai, Jiangsu and Zhejiang, where the natural gas prices are among the highest. Secondly, most likely, majority of the future NGCC plants will be also located in the eastern part of China because NGCC plants emit less $\mathrm{SO}_{2}$ and $\mathrm{NO}_{x}$ than coal-fired power plants, and the eastern regions in China are heavily impacted by the air pollution issues. Promoting NGCC plants to replace coal-fired plants in those regions will be a primary contribution to mitigating local air pollution.

Based on calculations provided in Table 3, the costs for advanced nuclear, wind, solar PV and biomass are estimated to be US\$65.4/MWh, US $\$ 63.7 / \mathrm{MWh}, \mathrm{US} \$ 103.7 /$ MWh and US\$87.2/MWh, respectively. In the EPPA model, there is an improvement in power production efficiency. EPPA use an autonomous energy efficiency improvement (AEEI) rate of $0.3 \%$ per year for electricity sector in China. The AEEI rate represents the long-run rate of efficiency improvement attribute to technological change and capital stock turn over. Some additional efficiency improvement will be price-driven, as higher fuel prices will lead to more capital use to increase efficiency of production. As mentioned before, the EPPA model includes two other channels that

${ }^{1}$ Costs are converted into 2010 yuan using GDP deflator from International Monetary Fund (IMF, 2015). 


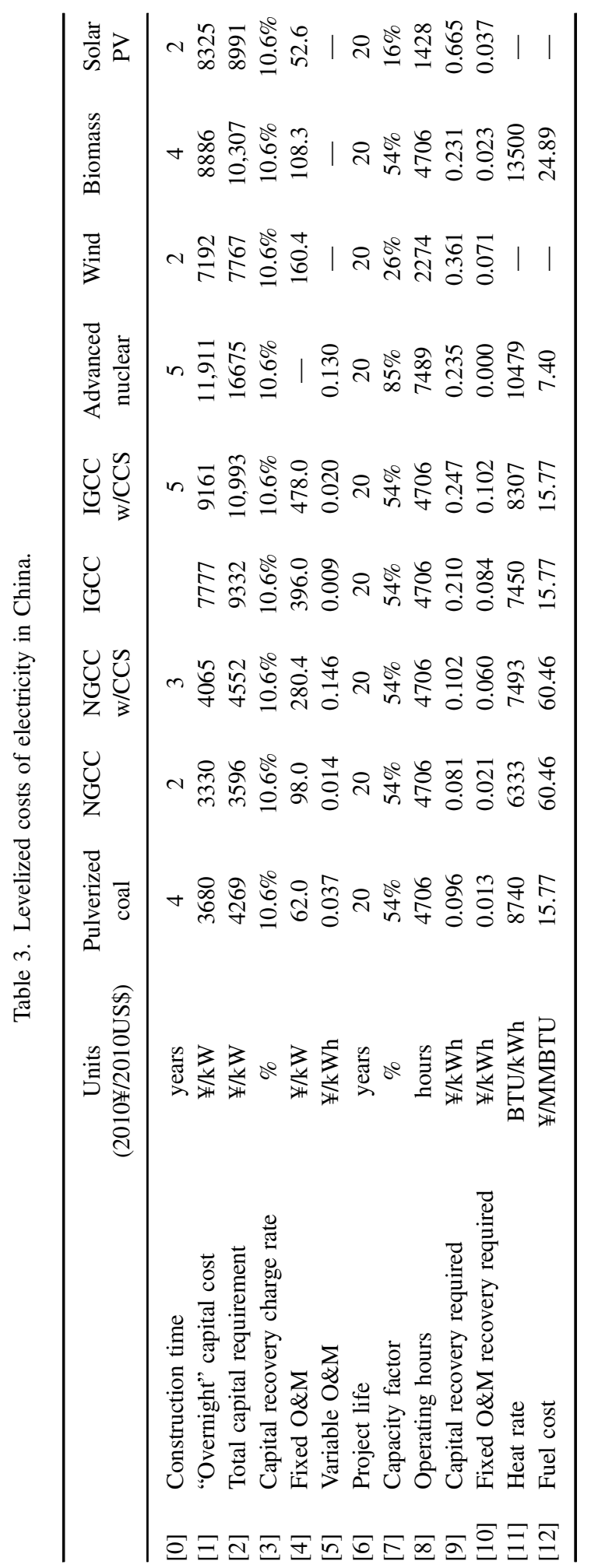




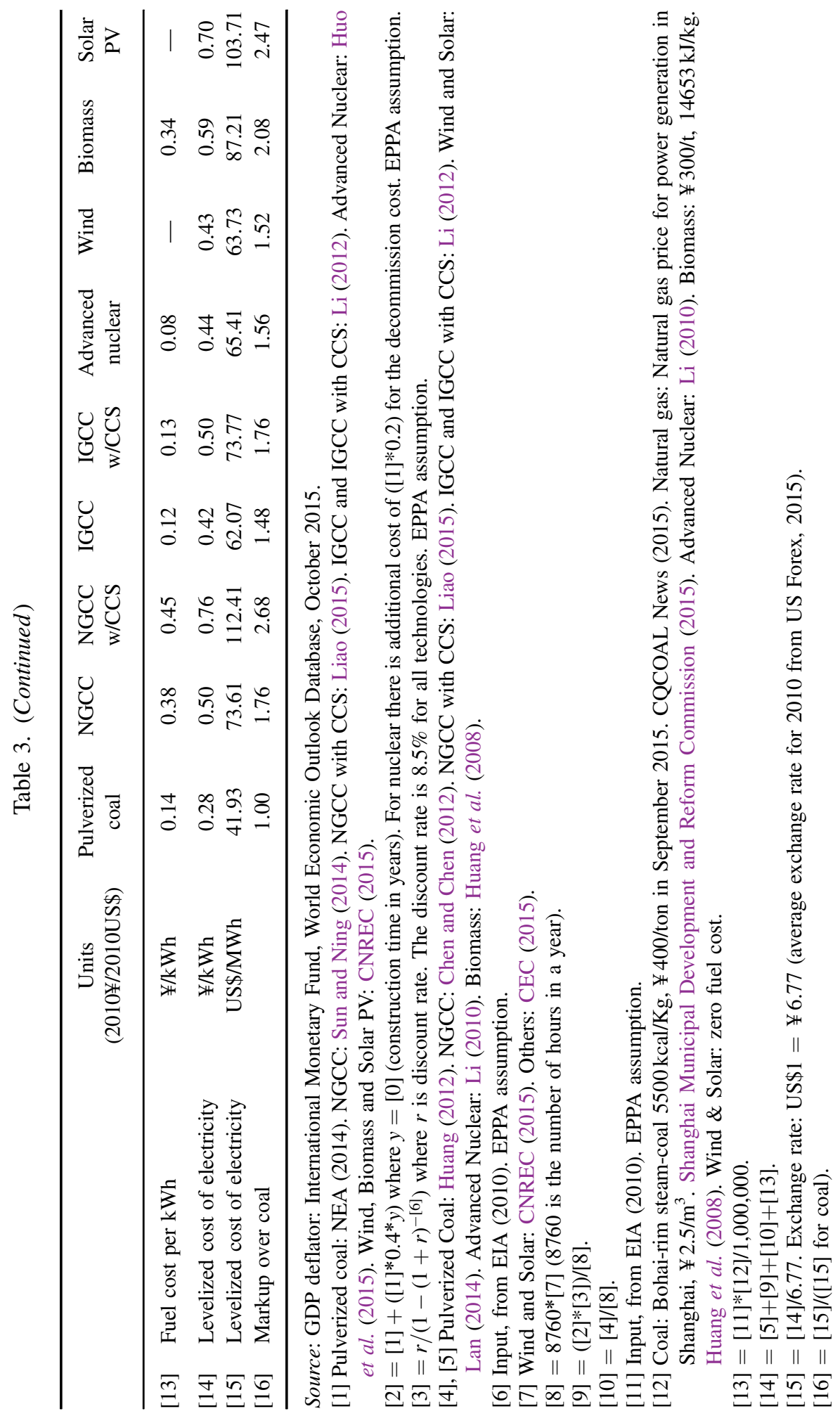


also affect efficiency of power plants: exogenous factor-augmented productivity growth and a technology specific factor that is parameterized to capture key observations of technology penetration such as gradual penetration, falling costs from the first-of-thekind plant to $n$th plant, etc. (Morris et al., 2014).

The EPPA model has a simplified representation of the electricity dispatch decisions. In China there is a large fraction of must-run combined heat and power coal-fired plants, as well as institutional factors such as inflexible pricing and grid operation norms and procedures that affect the dispatch decisions. Capturing this level of detail requires an electricity dispatch model that can resolve hourly profiles of the load, calculate ramping and reserve costs, and reflect the policies for the must-run baseload units. Changes in electricity system design, pricing and operations would provide greater flexibility and may affect the results for generation profiles in China (Davidson et al., 2016). While in this study we reflect the current dispatch practices in China, there is a need for a greater temporal and spatial representation to refine the deployment decisions.

In the current version of EPPA (Chen et al., 2015), natural gas is treated as a fuel which will be fully combusted in all intermediate and final consumption sectors. However, in China around 30\% of the natural gas input in industry is used as feedstock to produce chemicals such as acetylene and chloromethane (NBS, 2014). The difference between feedstock input and fuel input is important for the resulting emissions. Feedstock inputs are not combusted and they emit little GHG. Assuming that all natural gas is being used as a fuel will overestimate the amount of greenhouse emissions in the manufacturing sector.

In order to disaggregate the gas consumption into fuel input and feedstock input based on their actual usage, we introduce a new commodity titled "feedstock gas" into the production function in the energy-intensive (EINT) sector (see Fig. 2) of the EPPA model. The feedstock gas comes from a combination of both domestic gas and imported gas. Since feedstock gas is a non-energy commodity, it is aggregated in the same layer with other non-energy inputs. We adjust accordingly the amount of natural gas that is used as fuel.

Energy consumption (both fossil and nonfossil) in 2010 in the standard EPPA model (Chen et al., 2015) is calibrated to match the IEA data (IEA, 2012). In September 2015, the National Bureau of Statistics of China (NBS) released the official revision of energy consumption data from 2000 to 2013 (IMF, 2015). The revised statistics suggest that coal consumption has been underreported up to $17 \%$ each year compared to the data previously released by the (NBS, 2014, 2015a). Figure 3 presents China's primary energy consumption from 2005 to 2014 based on the revised statistics. China's energy mix is dominated by coal: in 2014, approximately $66 \%$ energy consumption came from coal. Natural gas contributed 242.8 Mtce, or $5.7 \%$ of China's primary energy consumption, which is much lower than the global average of $23.7 \%$ in 2014 (BP, 2015). During the 2005-2014 time frame, China's natural gas consumption grows at a $16.2 \%$ annual rate, while its total energy consumption grows by $5.6 \%$ per year. 


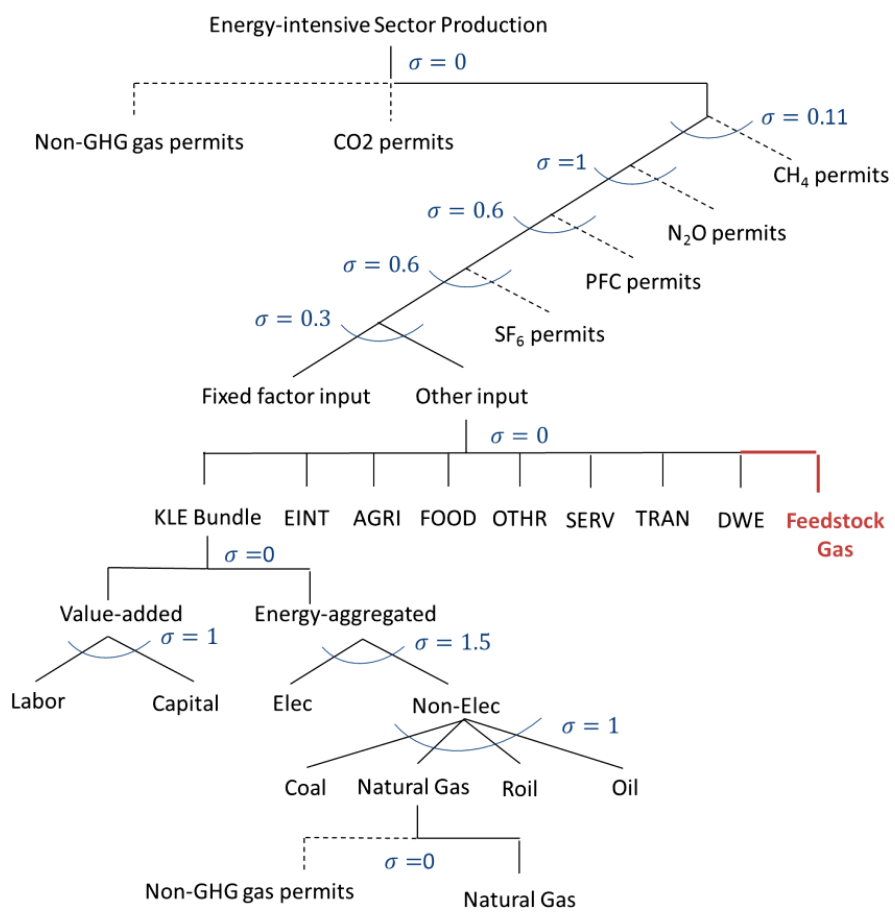

Figure 2. Production structure for energy-intensive sector (EINT) in EPPA.

We calibrated the energy consumption of China in 2010 according to the latest official data. Starting from 2010, EPPA runs in five-year intervals. Although the official statistics for annual energy consumption in 2015 are not available yet, we use the 2014 energy consumption as a base to calibrate the 2015 energy consumption. The National Energy Agency (NEA) of China estimates that the energy consumption in the first half

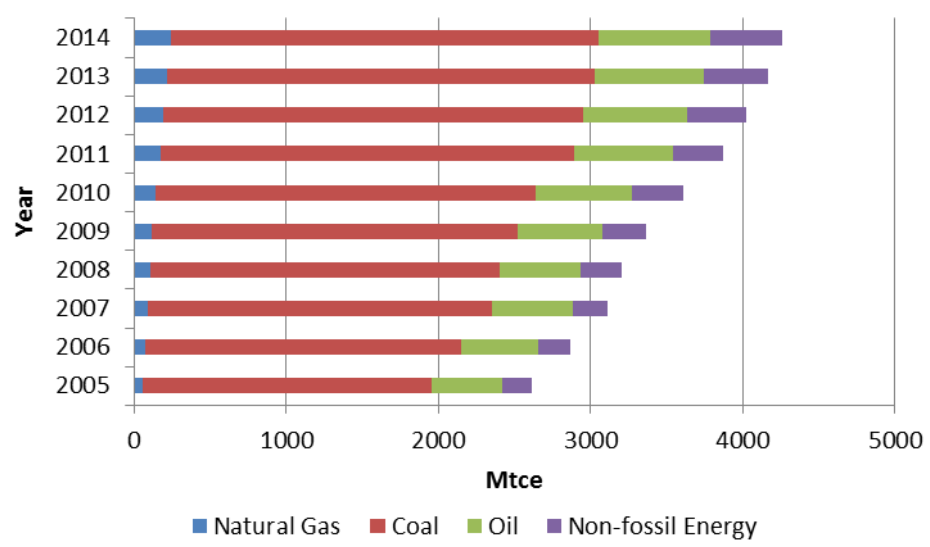

Data source: NNBS (2015b).

Figure 3. Natural gas in China's total energy supply (Mtce). 
of 2015 is $0.7 \%$ higher than the first half of 2014 . The NEA also estimates that energy consumption in the second half of 2015 will grow more than $0.7 \%$ from that in the second half year of 2014 (NEA, 2015). The total energy consumption in 2014 is 4260 Mtce (124.85 EJ), with an energy mix of $66 \%$ coal, $17.1 \%$ oil, $5.7 \%$ natural gas and $11.2 \%$ nonfossil energies (NNBS, 2015b).

Nuclear energy is calibrated to match the projected installed capacity in 2015 (SGCC, 2015) and 2020 (State Council of China, 2014). Nuclear energy from 2025 to 2050 are calibrated to match the High nuclear scenario from Paltsev and Zhang (2015b). Hydro power is calibrated to match the installed capacity projected by Zhang et al. (2016) from 2015 to 2050 and it reaches $400 \mathrm{GW}$ by 2050 . There are substantial uncertainties about wind and solar development. According to Chinese government, the installed capacities of wind and solar will reach $200 \mathrm{GW}$ and $100 \mathrm{GW}$, respectively by 2020 (State Council of China, 2014). Therefore, wind and solar are calibrated to the planned capacity provided by the government. Wind and solar energy consumption after 2020 are endogenously determined by the model. Due to the lack of information, we did not recalibrate biomass energy consumption. Therefore, bioelectricity and bio oil consumption in 2010 are still matched to the historic data presented in the IEA 2012 Energy Outlook. The targets that are used for calibration are summarized in Table 4.

The GTAP dataset is based on 2007 and it does not reflect the rapid natural gas development in China that occurred after 2007. To better reflect the current natural gas prices in China, we introduced a correction factor that adjusts the domestic price level by $28 \%$. This correction leaves the values from the GTAP unchanged, but increases the corresponding amount of natural gas in physical units. The correction amount is chosen to match China's statistics in 2010 (Paltsev and Zhang, 2015a).

In the standard EPPA model, the share of imported gas in 2015 does not reflect the real natural gas supply situation in China. Imported natural gas has increased rapidly since the Central Asia-China pipeline started operations in 2010. However, even with additional adjustments as described previously, the model fails to capture this infrastructure development. Based on the GTAP data, the standard EPPA model keeps the share of imported gas at $12 \%$ in 2015, which is much lower than the $31 \%$ import share in 2013 reported by the Chinese statistics (Paltsev and Zhang, 2015a). Since most of the increased gas imports are from Central Asia, we increased the bilateral trade flow between Central Asia and China in 2015 by $840 \%$ relative to the 2010 level.

Table 4. Projected installed capacity of nonfossil energies in China (GW).

\begin{tabular}{lrcrc}
\hline & 2015 & Source & 2020 & Source \\
\hline Wind & 100 & (State Council, 2013) & 200 & (NDRC, 2015) \\
Solar & 35 & (BJX News, 2015) & 100 & (NDRC, 2015) \\
Hydro & 300 & (State Council, 2013) & 350 & (NDRC, 2015) \\
Nuclear & 30 & $($ SGCC, 2015) & 58 & (NDRC, 2015) \\
\hline
\end{tabular}


This number is justified by the fact that, during the first 10 months in 2010, China imported a total value of US\$0.75 billion (Urumqi Customs, 2011) from Central Asia. In 2015 , the number has grown by $840 \%$, reaching US\$7 billion (Urumqi Customs, 2015). Even after increasing the value for the imported gas from Central Asia based on the custom statistics, the share of total gas imports in 2015 was still less than $31 \%$. Hence, another adjustment was made to reflect the growth in LNG imports.

\section{China's Natural Gas Future: Alternative Policy Scenarios}

\subsection{Description of scenarios}

We focus on the following three main scenarios which indicate three representative paths of China's future natural gas development: Reference, CapOnly (also referred as climate policy), and Cap+Subsidy (also referred as integrated policy). Table 5 summarizes the description of three scenarios.

\subsubsection{Reference scenario}

Under the Reference scenario, the natural gas pricing will be based on the oil-linked approach during 2015-2020, and completely market-determined afterwards. No

Table 5. Assumptions and highlights of the three typical policy scenarios.

\begin{tabular}{|c|c|c|c|}
\hline & Reference & CapOnly & Cap + Subsidy \\
\hline [1] & $\begin{array}{l}\text { Oil-linked gas price from } \\
2015 \text { to } 2020 \text {, market- } \\
\text { determined gas price } \\
\text { after } 2020\end{array}$ & The same as in Reference & The same as in Reference \\
\hline [2] & No carbon cap & $\begin{array}{l}\text { Carbon cap-and-trade } \\
\text { scheme introduced to } \\
\text { achieve a } 4 \% \mathrm{CO}_{2} \text { in- } \\
\text { tensity reduction per } \\
\text { year after } 2020\end{array}$ & The same as in CapOnly \\
\hline [3] & No gas subsidy & No gas subsidy & $\begin{array}{l}\text { Allocate a part of carbon } \\
\text { revenue to subsidize } \\
\text { natural gas use to } \\
\text { achieve a } 10 \% \text { of nat- } \\
\text { ural gas contribution in } \\
\text { primary energy con- } \\
\text { sumption since } 2020\end{array}$ \\
\hline $\begin{array}{l}\text { Scenario } \\
\text { Remarks }\end{array}$ & $\begin{array}{l}\text { Represents the current } \\
\text { natural gas pricing } \\
\text { approach and future } \\
\text { directions for pricing. }\end{array}$ & $\begin{array}{l}\text { Introduces a cap-and-trade } \\
\text { scheme to achieve } \\
\text { China's pledge - } \\
\text { peaking its } \mathrm{CO}_{2} \text { emis- } \\
\text { sion around } 2030 .\end{array}$ & $\begin{array}{l}\text { Integrated climate mitiga- } \\
\text { tion and natural gas } \\
\text { promotion policy is } \\
\text { introduced to achieve } \\
\text { the objective of climate } \\
\text { mitigation and natural } \\
\text { gas promotion simul- } \\
\text { taneously. }\end{array}$ \\
\hline
\end{tabular}




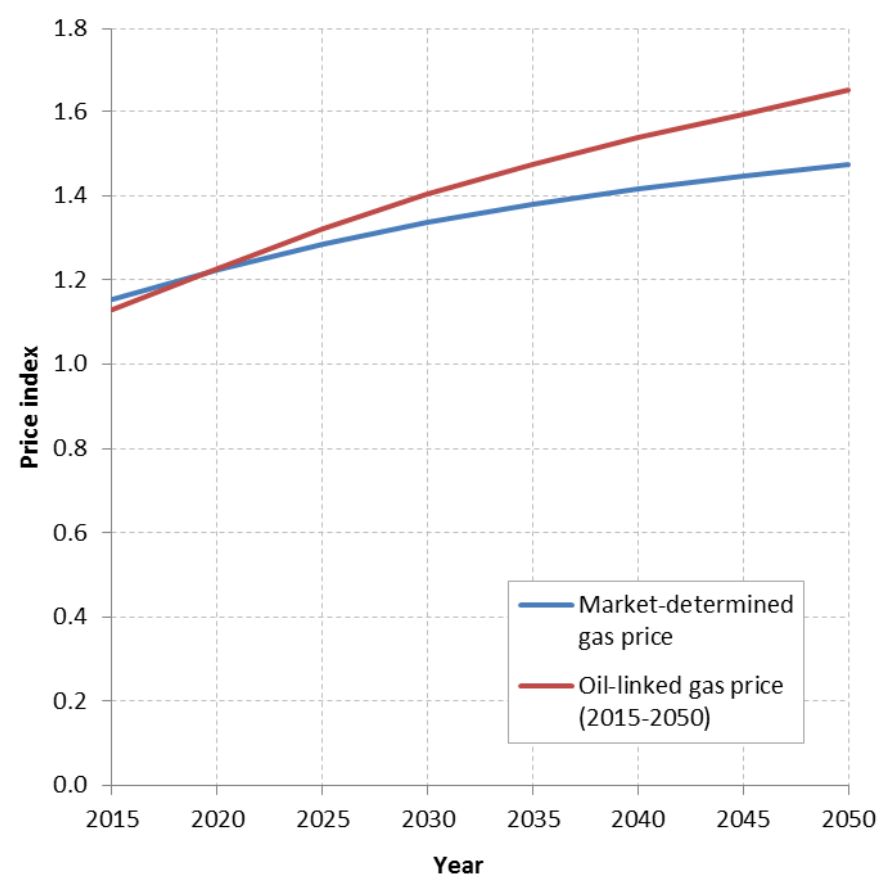

Figure 4. Price index of natural gas in the Market-Determined and Oil-Linked settings.

policies are introduced - the Reference scenario is used as a base case to assess the effects of the $\mathrm{CO}_{2}$ cap and natural gas consumption subsidies. Most of the results in this paper will be presented as deviations from the Reference.

There are several reasons why we link the natural gas price with the imported refined oil price during the 2015-2020 time frame. As shown in Fig. 4, the oil-linked natural gas price grows faster than the market-determined gas price after 2020, and there is an increasing deviation between the two price trajectories. This is due to differences in the supply and demand patterns for refined oil and natural gas. As the refined oil price increases faster than the natural gas price, keeping the natural gas price linked to the imported refined oil price would constrain natural gas consumption. This is not in line with the objective of China's natural pricing reform, which is to promote natural gas utilization.

China now encourages market-oriented energy system reform. NDRC and NEA are drafting the development plan for oil and natural gas reform for the 13th five-year plan period (2016-2020). The plan aims to establish a market-based pricing system covering the business of resource exploration, import, transmission and distribution (Xinhua News, 2015). In this regard, the current oil-linked natural gas pricing scheme should serve as a transition to a complete market-determined pricing system. Based on the modeling results and the government policies discussed above, a likely scenario is that China's natural gas price will be oil-linked during 2015-2020 timeframe and then will be market-determined after 2020 . 


\subsubsection{Climate policy scenario (CapOnly)}

China's INDC lists its major actions to address climate change. According to the INDC, China will decrease its carbon intensity by $60-65 \%$ from 2005 levels by 2030 , and peak its $\mathrm{CO}_{2}$ emissions around 2030. The INDC also cites establishing a nationwide emissions trading system (ETS) as a critical tool to enable China to achieve its INDC pledges (NDRC, 2015). The ETS will launch in 2017, according to the USChina Joint Presidential Statement on Climate Change (The White House, 2015).

By 2014, China achieved a $\mathrm{CO}_{2}$ intensity reduction of $33.8 \%$ compared to the 2005 levels (NDRC, 2015). If China achieves a carbon intensity reduction of about $4 \%$ per year during the period from 2015 to 2030, then it will accomplish a carbon intensity reduction of approximately $65.5 \%$ from 2005 to 2030 - very close to the range of its INDC $\mathrm{CO}_{2}$ intensity reduction pledge. Therefore, in the CapOnly scenario we use a $4 \% \mathrm{CO}_{2}$ intensity reduction rate as a constraint to generate $\mathrm{CO}_{2}$ cap in EPPA to simulate China's INDC starting in 2020.

\subsubsection{Integrated carbon cap-and-trade and natural gas subsidy policy scenario $($ Cap + Subisdy)}

The Cap+Subsidy scenario is designed to investigate the magnitude of support needed to meet China's natural gas target while implementing a nationwide ETS to achieve the INDC targets. The ETS caps $\mathrm{CO}_{2}$ emissions by generating a $\mathrm{CO}_{2}$ penalty. Fossil fuel consumption is expected to be substantially reduced with the implementation of ETS. Although natural gas has less carbon content than coal, it is still a carbon-emitting fossil fuel and is also expected to be reduced by a sizeable amount due to the $\mathrm{CO}_{2}$ penalty. As a result, China's climate policy might counteract its natural gas promotion policy, which aims to reach a $10 \%$ share of natural gas in the primary energy supply.

If the government intends to reduce $\mathrm{CO}_{2}$ emissions and increase natural gas consumption at the same time, it may need to subsidize natural gas consumption. Natural gas subsidy plays an important role in promoting natural gas utilization under climate policy. Burning coal generates more $\mathrm{SO}_{2}$ and particulates than natural gas. Therefore, natural gas subsidy is justified by the fact that it internalizes the air pollution externalities of coal.

In this scenario, in addition to the $\mathrm{CO}_{2}$ cap, we implement subsidies to natural gas consumption in all sectors except for the chemical manufacturing sector. This setting is intended to be in line with the government's natural use guidelines which have restrictions on gas use for chemical production (NDRC, 2012). In this scenario, the residential, energy intensive, electricity, transport, services and other sectors are subsidized for their natural gas consumption as fuel starting in 2020. We set the subsidy levels on different gas users until the total natural gas supply accounts for $10 \%$ of the total energy supply in each period after 2020. We also calculate the amount of subsidies as a share of $\mathrm{CO}_{2}$ tax revenue in each period. The results might be informative for policy makers to illustrate the amount of $\mathrm{CO}_{2}$ tax revenue (or $\mathrm{CO}_{2}$ permit revenue) 
which should be allocated to subsidize natural gas consumers and reach natural gas consumption targets. The results will be discussed in the next section.

In all scenarios, energy consumption in 2010 is calibrated to match the Chinese statistics released by National Bureau of Statistics (NNBS, 2015b). China's natural gas consumption in 2015 is calibrated to match projections based on the 2014 data. While in the Reference scenario we assume no climate policy, in both scenarios with $\mathrm{CO}_{2}$ policy we also implement the $\mathrm{CO}_{2}$ cap on the rest of the world to reflect the UN agreement in Paris in December of 2015. The emission caps on the other EPPA model regions are based on the MIT Energy and Climate Outlook 2015 (Reilly et al., 2015). In the regions that impose carbon policy, $\mathrm{CO}_{2}$ revenue is distributed in a lump sum manner.

Air pollution objectives can also be achieved by imposing taxes or regulations on air pollutants. In one previous application of the EPPA model, we explored $\mathrm{SO}_{2}$ and $\mathrm{NO}_{x}$ emission targets in China and their impacts on $\mathrm{CO}_{2}$ emissions (Nam et al., 2013) and found out that air pollution targets have substantial climate co-benefits, but the cost of achieving these targets can be quite high. In addition, these policies may result in a lock-in effect for the existing technology rather than in a promotion of alternative lowcarbon energy sources. Another application of the EPPA model (Nam et al., 2014) explored cross-elasticities of pollution and climate control with small $(10 \%)$ and more stringent $(75 \%)$ reduction targets. For China it illustrated the availability of pollution control technologies to target individual pollutants for smaller reduction but the need for wholesale change toward nonfossil technologies when large reductions are required. In this paper, we do not consider taxes on conventional air pollutants and rather focus on the policies and targets proposed by China regarding its $\mathrm{CO}_{2}$ emissions and natural gas promotion objectives.

\subsection{Results and discussion}

\subsection{1. $\mathrm{CO}_{2}$ emissions and carbon price}

As shown in Fig. 5, the $\mathrm{CO}_{2}$ cap-and-trade policy can substantially reduce $\mathrm{CO}_{2}$ emissions from the Reference case after 2020. This is because the policy creates a $\mathrm{CO}_{2}$ price which reflects the marginal cost of $\mathrm{CO}_{2}$ emission abatement. Under this policy scenario, the (explicit or implicit) $\mathrm{CO}_{2}$ price is added to all fossil energy used as a fuel. As a result, the energy price increases and consumers need to pay more when purchasing fossil energy. Subsidies encourage consumers to use more natural gas by creating an incentive for consumers to use less fossil fuel and cleaner types of energy such as wind, solar, nuclear and hydro. As the demand for fossil energy decreases, so do $\mathrm{CO}_{2}$ emissions.

The stringency of the $\mathrm{CO}_{2}$ mitigation policy in terms of a carbon intensity reduction rate is the same in the CapOnly scenario and the Cap+Subsidy scenario. Therefore, the trajectories for the $\mathrm{CO}_{2}$ emissions in both scenarios are also the same. However, the $\mathrm{CO}_{2}$ prices to achieve the $\mathrm{CO}_{2}$ emissions policy targets are somewhat different. In 

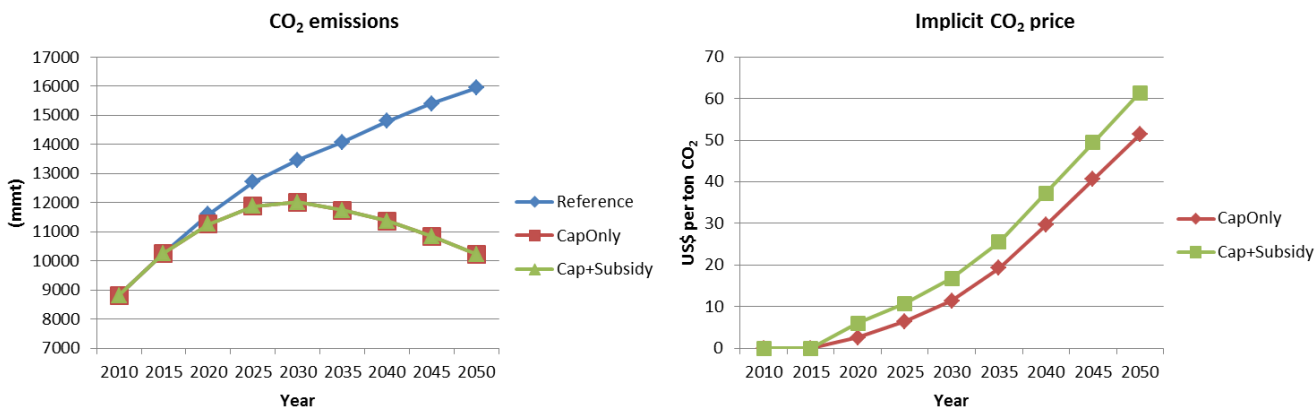

Figure 5. $\mathrm{CO}_{2}$ emissions and implicit $\mathrm{CO}_{2}$ price.

2030, the $\mathrm{CO}_{2}$ price to peak $\mathrm{CO}_{2}$ emissions is about $\$ 11.5 / \mathrm{tCO}_{2}$ in the CapOnly scenario, but it is $\$ 16.7 / \mathrm{tCO}_{2}$ in the Cap+subsidy scenario (see Fig. 5). Though natural gas is cleaner than coal, burning of natural gas still emits $\mathrm{CO}_{2}$. Under the same $\mathrm{CO}_{2}$ emissions constraint, the increased $\mathrm{CO}_{2}$ emission from the increased use of natural gas should be offset by the decreased emissions from the reduced use of other fuels, such as coal, which needs a higher $\mathrm{CO}_{2}$ price.

\subsubsection{Energy consumption}

Figure 6 compares energy consumption and total natural gas consumption in the three scenarios. As can be seen, the total energy consumption under the two policy scenarios is lower than under the Reference scenario. The difference in total energy consumption between the CapOnly scenario and the Cap+Subsidy scenario is not large. The energy consumption structure in the CapOnly scenario, however, is different from in the Cap+Subsidy scenario.

In the CapOnly scenario, in 2030 coal consumption decreases by $12 \%$ (from $110.8 \mathrm{EJ}$ to $97.9 \mathrm{EJ}$ ) and natural gas consumption by $40 \%$ (from $12.4 \mathrm{EJ}$ to $7.4 \mathrm{EJ}$ ), compared with the Reference. The share of natural gas in the primary energy supply declines from $6.5 \%$ to $4.2 \%$, which is much below the $10 \%$ natural gas target. Nonfossil energy use in 2030 climbs from $34.9 \mathrm{EJ}$ to $36.4 \mathrm{EJ}$, accounting for $20.8 \%$ of the

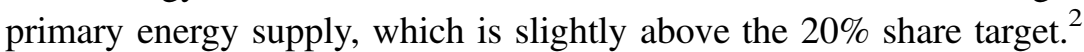

The Cap+Subsidy scenario suggests that natural gas can reach the $10 \%$ natural gas target in 2020 under substantial subsidies. The total subsidy amount accounts for about $10 \%$ of $\mathrm{CO}_{2}$ revenue in 2020 (we discuss the amount of subsidies later in more detail). With subsidy, natural gas consumption can climb to $18.9 \mathrm{EJ}$ in 2030 in the Cap +Subsidy scenario, which is $52.5 \%$ higher than in the Reference scenario and $155.6 \%$ higher than in the CapOnly scenario. The coal consumption in the Cap + Subsidy scenario is reduced by 19.3 EJ relative to the Reference scenario and by

${ }^{2}$ INDC sets the goal to increase the share of non-fossil fuels in primary energy consumption to around $20 \%$ by 2030 (NDRC, 2015). 


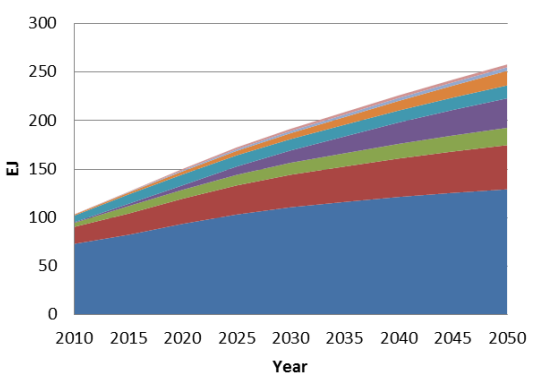

(a)

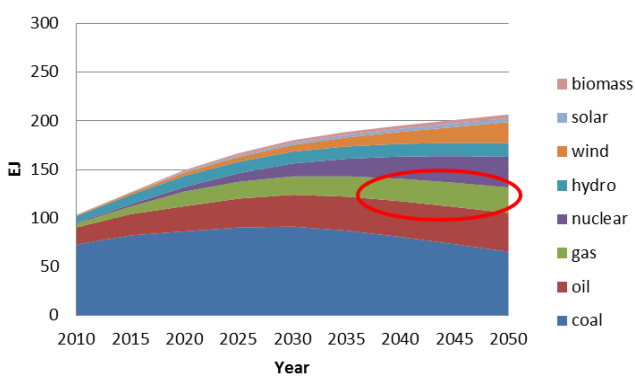

(c)

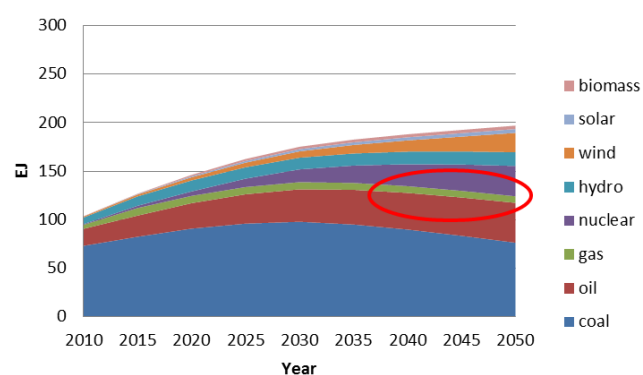

(b)

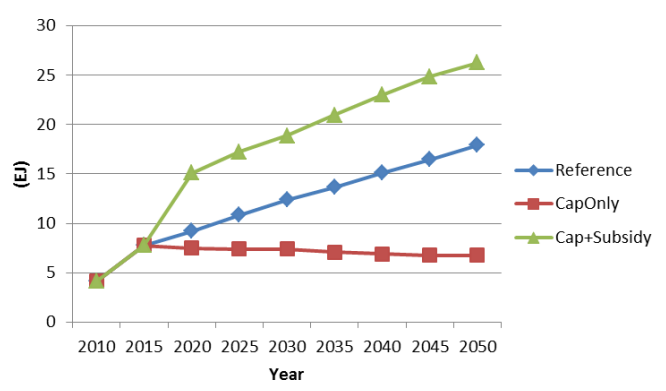

(d)

Figure 6. Energy consumption by fuel under different scenarios. (a) Energy consumption by type, Reference, (b) Energy consumption by type, CapOnly, (c) Energy consumption by type, Cap+Subsidy and (d) Total gas use.

6.4 EJ relative to the CapOnly scenario in 2030, indicating that gas subsidy plays a vital role in promoting natural gas substitution for coal. The nonfossil energy supply in the Cap+Subsidy scenario increases by $2.1 \mathrm{EJ}$ and by $0.7 \mathrm{EJ}$ compared with in the Reference scenario and the CapOnly scenario in 2030, respectively. This demonstrates that natural gas subsidy plus a higher carbon tax results in a coal consumption reduction as well as an increase of nonfossil energy supply.

\subsubsection{Changes in coal and natural gas use}

In the CapOnly scenario, an introduction of a $\mathrm{CO}_{2}$ price improves a competiveness of natural gas with coal due to a lower carbon content of natural gas. But the resulting carbon price level is still not high enough to offset the large initial price difference between natural gas and coal. As shown in Fig. 7(a), a $\mathrm{CO}_{2}$ price reduces both coal and natural gas consumption. One sector where carbon pricing may introduce a switch from coal to natural gas is electricity. In China, the NGCC generation cost almost twice as pulverized coal-fired electricity generation technology. Since the natural gas-fired electricity is much more expensive than coal-fired electricity, a relatively low $\mathrm{CO}_{2}$ price is not able to induce the coal-to-gas switching in the power sector. Compared with the CapOnly scenario, natural gas consumption rises while coal consumption declines in the integrated policy scenario, as shown in Fig. 7(b). 


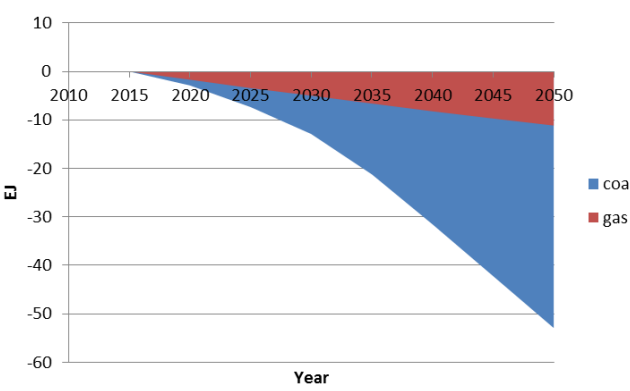

(a)

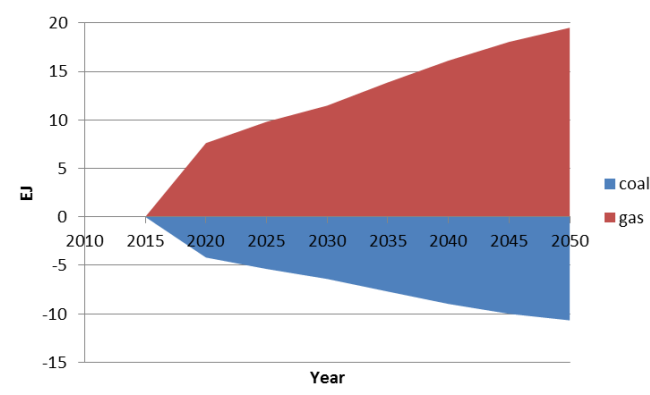

(b)

Figure 7. Change in coal and natural gas consumption in different scenarios. (a) Difference between CapOnly \& Reference and (b) Difference between Cap+Subsidy \& CapOnly.

\subsubsection{Natural gas consumption by sector}

Natural gas consumption patterns are significantly different among the three scenarios. As represented in Fig. 8, natural gas use declines substantially in the CapOnly scenario with the introduction of climate policy without gas subsidies, from $12.4 \mathrm{EJ}$ to $7.36 \mathrm{EJ}$ in 2030. Natural gas use in the household sector is reduced the most, from $2.5 \mathrm{EJ}$ in the Reference scenario to $0.5 \mathrm{EJ}$ in the CapOnly scenario in 2030. The residential sector appears to be the most sensitive to natural gas price changes, while natural gas use in chemical manufacturing sector is hardly affected by the $\mathrm{CO}_{2}$ price. That is because the natural gas used as feedstock does not emit $\mathrm{CO}_{2}$ and is not a subject to carbon penalty. Change in natural gas use in the electricity generation sector is relatively small because while $\mathrm{CO}_{2}$ price imposes penalty on both natural gas and coal, natural gas is less affected as it has lower carbon content than coal.

In the integrated policy case, the $\mathrm{CO}_{2}$ penalty for natural gas users is offset by the gas subsidy, which makes natural gas more competitive than coal for consumers. As a result, a substitution of natural gas for coal happens, especially as a fuel in the energyintensive sector and in the household sector. Compared with the CapOnly scenario, natural gas consumption under the Cap+Subsidy scenario increases by $11.5 \mathrm{EJ}$ in 2030 and by $19.5 \mathrm{EJ}$ in 2050. Table 6 shows the amount of increased natural gas consumption by sector in the integrated policy case relative to the climate policy scenario. A large amount of the increased natural gas use takes place in the residential sector, power generation and industrial sector.

\subsubsection{Natural gas supply by source}

Domestic production and imports of natural gas are substantially affected by a choice of the policy instrument, as shown in Fig. 9. In the CapOnly scenario, both imported and domestic natural gas use are substantially decreased due to the reduced demand (Fig. 9(b)), because both the imported natural gas and domestic natural gas are subject to a carbon price penalty. Imports of natural gas decrease more than a decline in 


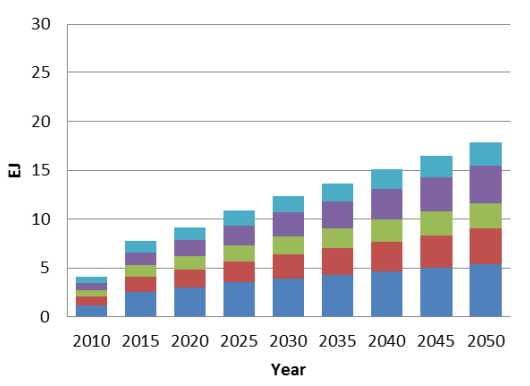

(a)

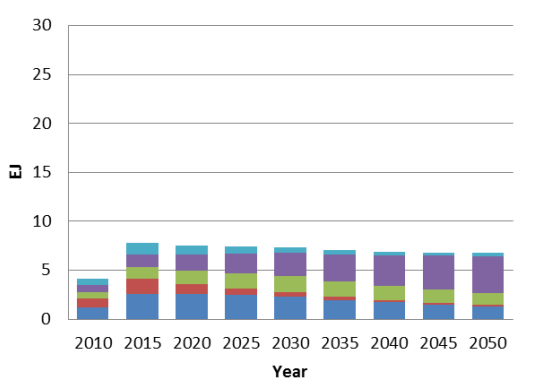

(c)

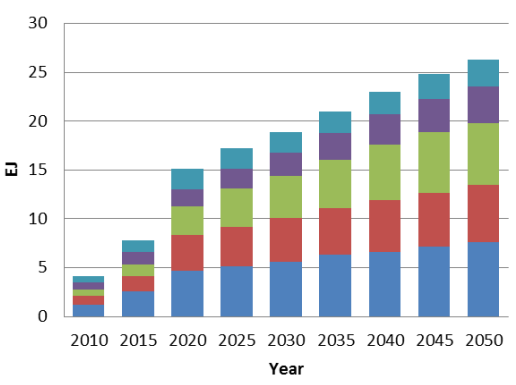

(e)

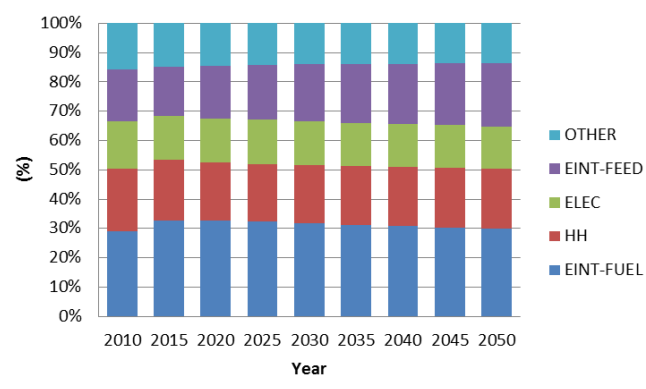

(b)

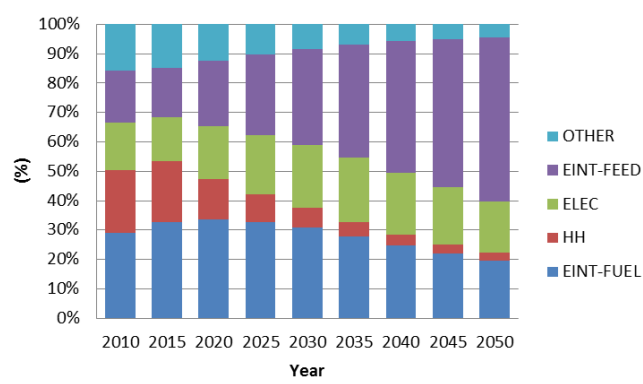

(d)

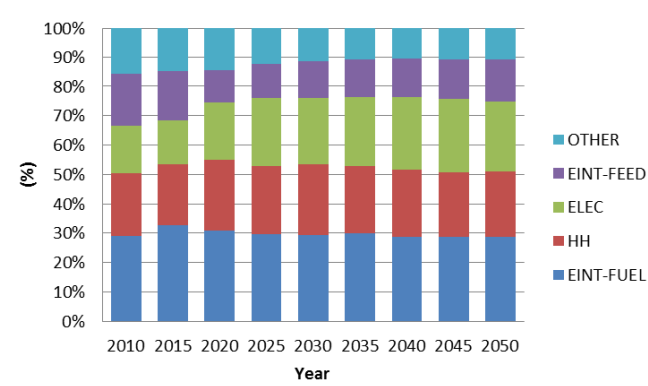

(f)

Figure 8. Natural gas consumption by sector in different scenarios. ${ }^{3}$ (a) Natural gas consumption by sector, Reference, (b) Natural gas consumption by sector (\%), Reference, (c) Natural gas consumption by sector, CapOnly, (d) Natural gas consumption by sector (\%), CapOnly, (e) Natural gas consumption by sector, Cap+Subsidy and (f) Natural gas consumption by sector (\%), Cap+Subsidy.

domestic production. While in this scenario some imports remain, international natural gas trading flows re-allocate from China to the destinations without (or with less stringent) carbon policies (ASI and IDZ regions of the EPPA model).

\footnotetext{
${ }^{3}$ The OTHER category includes the following sectors: TRAN, CROP, LIVE, FORS, FOOD, ROIL, OTHR and SERV. EINT-FEED reports natural gas used as feedstock. EINT-FUEL represents energy intensive sectors that use natural gas as fuel. HH represents household sector (HHTRAN, DWE, HHOTHR). See Table 1 for sectoral definition.
} 
Table 6. Increase in gas consumption in Cap+Subsidy compared to CapOnly (EJ).

\begin{tabular}{lccccccc}
\hline (EJ) & 2020 & 2025 & 2030 & 2035 & 2040 & 2045 & 2050 \\
\hline EINT-FUEL & 2.2 & 2.7 & 3.3 & 4.3 & 4.9 & 5.6 & 6.3 \\
OTHER & 1.2 & 1.3 & 1.5 & 1.7 & 1.9 & 2.3 & 2.5 \\
ELEC & 1.6 & 2.5 & 2.7 & 3.4 & 4.2 & 4.9 & 5.1 \\
HH & 2.6 & 3.3 & 4.0 & 4.5 & 5.1 & 5.3 & 5.7 \\
\hline
\end{tabular}

Under the integrated scenario, the gas subsidy scheme boosts both domestic and imported supply (Fig. 9(c)). The subsidy scheme lowers the price that consumers pay for gas, increasing the competitiveness of natural gas relative to coal and oil. As a result, demand for natural gas grows, where a large part of the increased demand is met by imported gas because of domestic supply capacity constraints. With a limited increase in domestic production, gas suppliers need to increase the imported volumes to meet the surging demand. In 2050, domestic production is $9.0 \mathrm{EJ}$ and imports are

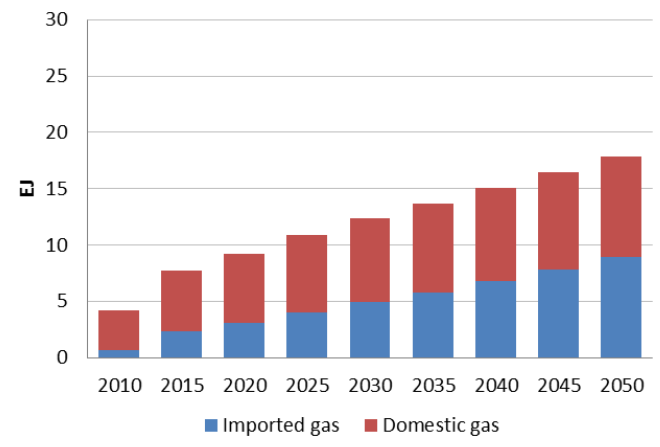

(a)

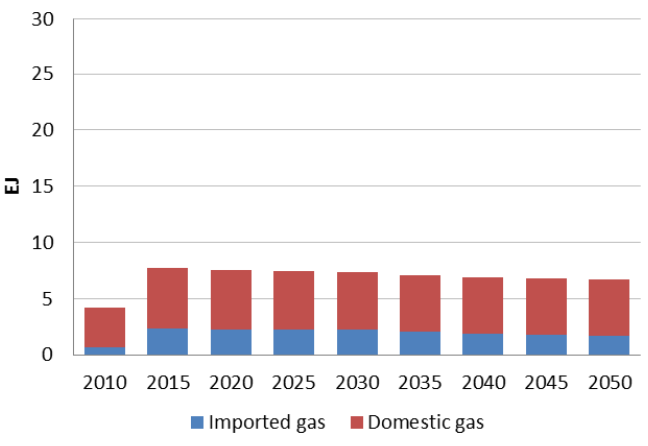

(b)

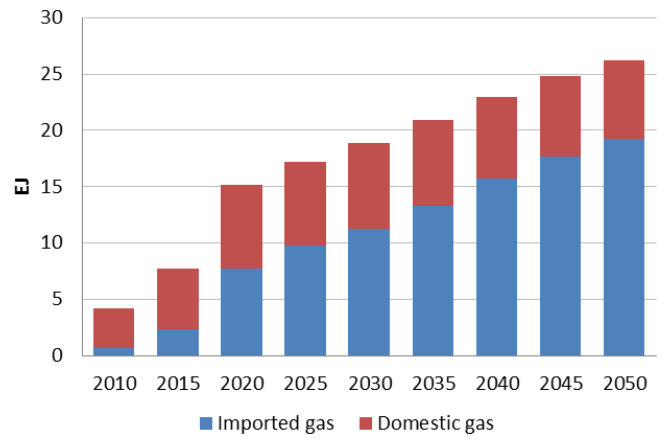

(c)

Figure 9. Domestic and imported natural as supply in different scenarios. (a) Natural gas supply by source, Reference, (b) Natural gas supply by source, CapOnly and (c) Natural gas supply by source, Cap+Subsidy. 
8.9 EJ in the Reference scenario. They are 5.0 EJ and 1.7 EJ in the CapOnly scenario, and 7.1 EJ and 19.2 EJ in the Cap+Subsidy scenario.

\subsection{6. $\mathrm{NO}_{x}$ and $\mathrm{SO}_{2}$ emissions}

$\mathrm{NO}_{x}$ and $\mathrm{SO}_{2}$ emissions are largely attributed to burning of fossil fuels. The climate policy will cap the $\mathrm{CO}_{2}$ emissions and fossil fuel use; thus, $\mathrm{NO}_{x}$ and $\mathrm{SO}_{2}$ emissions to a large extent are also going to be reduced (Fig. 10). Under the climate policy scenario, $\mathrm{NO}_{x}$ emissions and $\mathrm{SO}_{2}$ emissions decline by $3.3 \%$ and $4.6 \%$ in 2030 and by $11.6 \%$ and $14.1 \%$ by 2050 , respectively, compared with the Reference scenario. The integrated policy can result in larger reductions in air pollutant emissions: $5.5 \%$ in 2030 and $14.0 \%$ in 2050 for $\mathrm{NO}_{x}$ emissions and $7.0 \%$ in 2030 and $16.7 \%$ in 2050 for $\mathrm{SO}_{2}$ emissions, relative to the Reference scenario. The reduction is mostly attributed to a substantial substitution of natural gas for coal which takes place in the integrated policy case. These results also show that carbon policies that induce fuel use reduction and fuel switching are able to lower air pollution emissions substantially, but additional policies that directly target air pollution (especially in the process-related emissions in energy-intensive sectors) are required for further lowering air pollution.
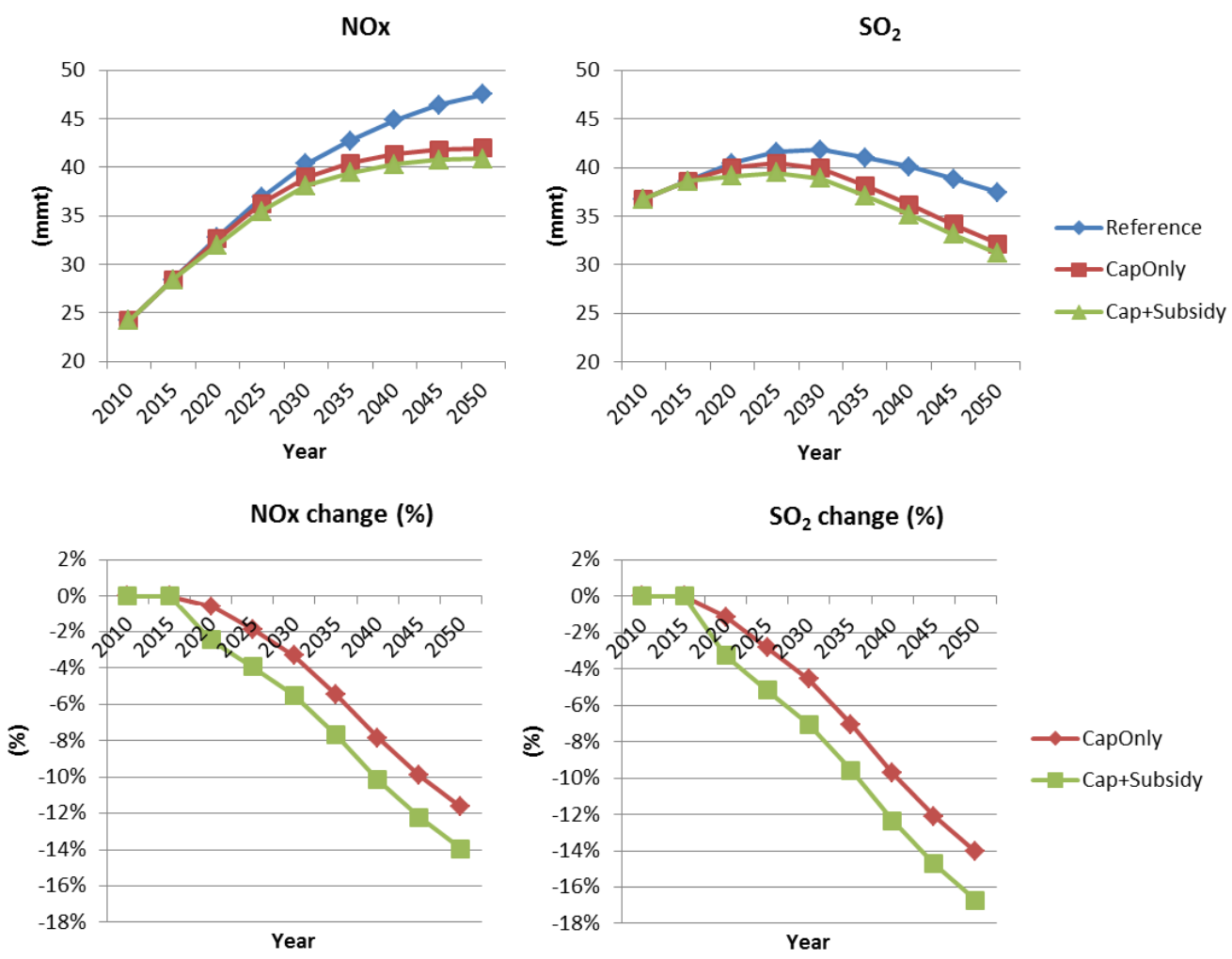

Figure 10. $\mathrm{NO}_{x}$ and $\mathrm{SO}_{2}$ emissions. 


\subsubsection{Policy cost}

Welfare change is a measure of climate policy cost (Paltsev and Capros, 2013). Following standard economic theory, we calculate and report the overall economic cost of the policy scenarios using a dollar-based measure of the change in welfare for the representative agent in China. In technical terms, welfare is measured as equivalent variation and it reflects a change in aggregate market consumption activity. Introducing carbon constraints brings the increases in the fossil energy prices because their consumer prices include carbon charges. Energy users pay more for energy, and additional investment in low-carbon technologies lead to reallocation of resources in China's economy, which ultimately leads to welfare losses in the CapOnly and Cap+Subsidy scenarios relative to the Reference scenario (Fig. 11). The model simulations result in a $0.27 \%$ welfare loss in 2030 and a $0.38 \%$ welfare loss in 2050 in the CapOnly scenario. The welfare loss is higher in the Cap+Subsidy case: $0.31 \%$ in 2030 and $0.57 \%$ in 2050 relative to the Reference scenario. The integrated policy creates a mechanism that subsidizes relatively expensive natural gas and reduces further the use of relatively cheaper coal, which results in an additional welfare cost. Our welfare results do not
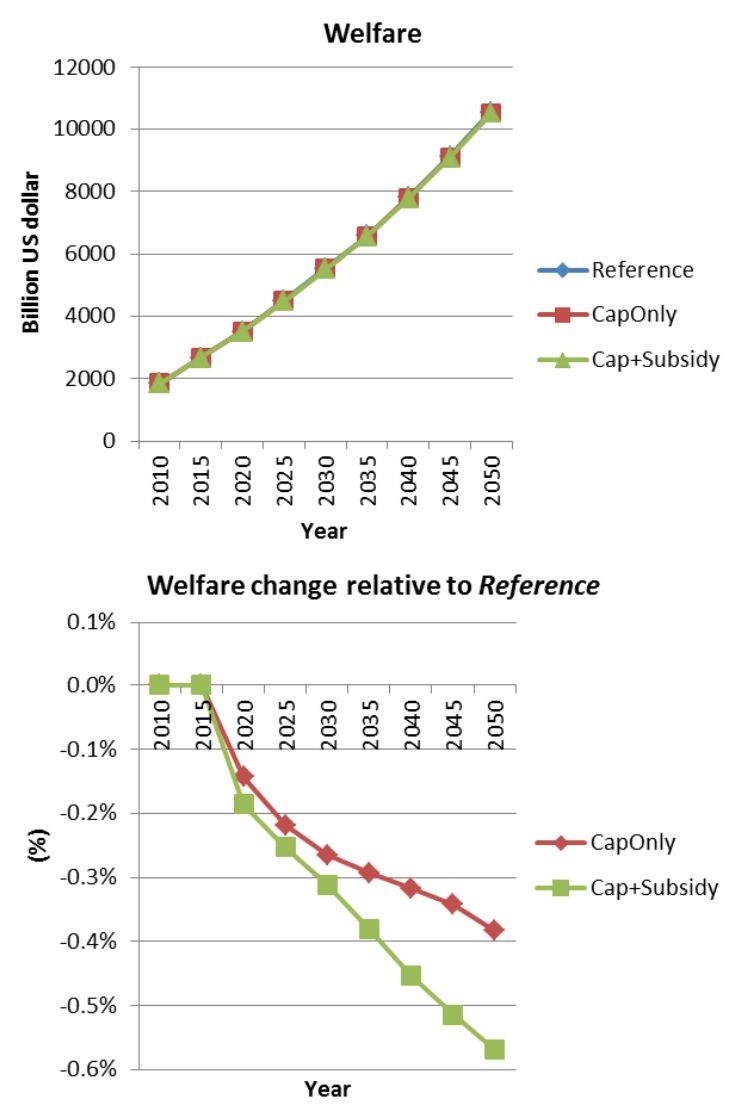

Figure 11. Welfare (consumption) change. 
account for health benefits associated with air pollution, which can be substantial. The welfare loss numbers presented here can be reduced or compensated if the environmental benefits associated with lower air pollution are taken into account. Valuing these benefits is a challenging task (Matus et al., 2012) which is beyond the scope of this study.

There is a growing body of literature that focuses on the impacts of air pollution in China. The studies agree on large welfare costs for the society. As mentioned, some studies estimate that air pollution in China contributes to 1.2 million (Yang et al., 2013) to 1.6 million (Rohde and Muller, 2015) deaths per year. Other researchers (Chen et al., 2013) used the quasi-experimental empirical approach that is based on China's Huai River policy, which provided free winter heating via the provision of coal for boilers in cities north of the Huai River but denied heat to the south. They concluded that the 500 million Chinese who live north of the Huai River are set to lose an aggregate 2.5 billion years of life expectancy due to the extensive use of coal. Matus et al. (2012) attempts to assess the economic losses from air pollution and finds that PM and ozone have substantially impacted the Chinese economy. Quantifying costs from lost labor and the increased need for health care, the study finds that this air pollution cost the Chinese economy \$112 billion in 2005, compared to \$22 billion in such damages in 1975.

Researchers also try to quantify the economic damages associated with $\mathrm{CO}_{2}$ emissions. US EPA uses the social cost of carbon estimate (EPA, 2015) that ranges from $\$ 11$ to $\$ 56$ per ton of $\mathrm{CO}_{2}$ in 2015 to $\$ 26$ to $\$ 95 / \mathrm{tCO}_{2}$ in 2050 (recall that carbon prices reported in Fig. 4 grow to about $\$ 50-60 / \mathrm{tCO}_{2}$ in 2050). Similarly to estimating the damages from air pollution, the social cost of carbon estimate suffers from the current modeling and data limitations. The current assessments do not include all of the important physical, ecological and economic impacts of climate change recognized in the climate change literature because of a lack of precise information on the nature of damages and because the science incorporated into these models naturally lags behind the most recent research (EPA, 2015).

\subsubsection{Level of subsidy}

Based on the modeling results, the subsidy amount required to achieve the $10 \%$ natural gas goal is $\$ 5.0$ billion in 2020, $\$ 12.2$ billion in 2030 and $\$ 51.3$ billion in 2050, respectively (Fig. 12). To finance such amount of subsidy, the Chinese government may need to secure new income sources. The $\mathrm{CO}_{2}$ tax revenue (or proceeds from the sales of $\mathrm{CO}_{2}$ emission permits) can be used for such a new source of government revenue. In the policy scenarios, China's government earns about $\$ 66$ billion from the emission permit sales in 2020, $\$ 200$ billion in 2030, and $\$ 618$ billion in 2050 . Therefore, the Chinese government would need to allocate $6 \%$ to $9 \%$ of its $\mathrm{CO}_{2}$ permits revenue to subsidize natural gas consumers to achieve its natural gas promotion goal.

Based on the EPPA model simulation, the total natural gas subsidy would account for approximately $0.4 \%, 0.6 \%$ and $1.1 \%$ of the government's total government 


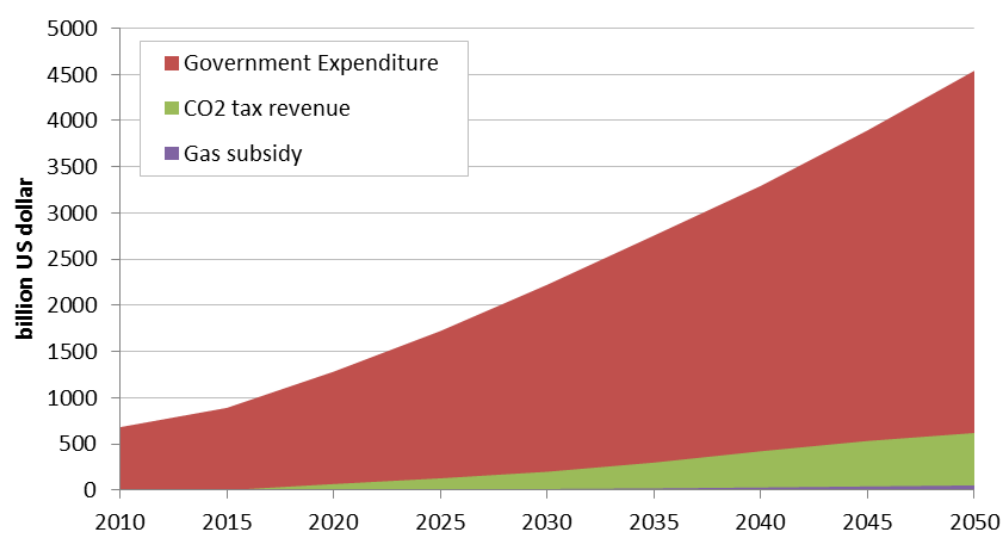

Figure 12. Level of subsidy.

expenditure in 2020, 2030 and 2050, respectively. It should be noted that the government expenditures in the EPPA model are based on the data from the underlying GTAP dataset (Narayanan et al., 2012), and these total expenditures should be roughly equal to the total government revenue. There is some discrepancy for the data on the government income. According to China's data, in 2014, the Chinese government's income was about $\$ 2000$ billion (NNBS, 2015b), which is somewhat higher than the government expenditure of about $\$ 1000$ in 2015 simulated from the model. A difference might be explained by different accounting definitions of central, provincial and local government activities. If the model underestimates government income, then the actual required natural gas subsidies constitute an even smaller share of the total government revenue.

\subsubsection{Sensitivity analysis}

We tested our findings for their sensitivity to policy design modifications, nuclear power development and cost of NGCC technology. Removing the household sector from the emission cap leads to an increase in consumption of a relatively cheap coal, rather than natural gas. Additional policy instruments are also required to achieve the objective of a larger natural gas share in consumption.

With technological advancement, the NGCC cost is expected to decrease. Currently, the levelized generation cost of NGCC is about $75 \%$ higher than generation cost of a coal-fired power plant (see Table 3). After testing different reductions in the NGCC costs, we find that to expand in a substantial way, natural gas technology should be no more than $15 \%$ more expensive than coal. Such reduction in cost differences might be achieved by natural gas technology improvement or by imposing penalties (like a $\mathrm{CO}_{2}$ price) on coal-based generation. By varying the $\mathrm{CO}_{2}$ price, we find that natural gas becomes competitive with coal at about $\$ 50 / \mathrm{tCO}_{2}$. The modeling results with various assumptions about the cost of NGCC confirm that with $75 \%$ cost difference between natural gas and coal, in 2030 the electricity sector consumes $1.9 \mathrm{EJ}$ of natural gas in the 
Reference scenario and 1.6 EJ in 2030 in the CapOnly scenario. With a cost difference of 5\%, in 2030 the electricity sector consumes 8.4 EJ in the Reference case and 15.3 EJ in the CapOnly case.

We also assessed the effects of different nuclear penetration rates on natural gas use in China. The results show that with a lower nuclear penetration rate, China needs a higher $\mathrm{CO}_{2}$ price to meet its $\mathrm{CO}_{2}$ intensity mitigation targets and the higher $\mathrm{CO}_{2}$ price discourages natural gas use. This sensitivity analysis illustrates a need for substantial flexibility and periodic assessments of the government targets depending on the realization of fuel prices and technological costs in the future. While a cap-and-trade system would put an absolute ceiling on the emission levels, some additional policy instruments may be introduced to lower the cost of reaching the targets.

\section{Conclusions}

China has pledged to mitigate its $\mathrm{CO}_{2}$ emissions by introducing a number of policy instruments including a national cap-and-trade system. Our analysis demonstrates that the introduction of the $\mathrm{CO}_{2}$ cap-and-trade scheme can be used to achieve China's INDC. However, it may also substantially reduce natural gas consumption as it imposes a penalty on all fossil fuels including natural gas. There are two main channels that affect the relative prices and the use of natural gas and coal. Carbon penalty makes coal and natural gas more expensive. As the prices for coal and natural gas increase, their use decreases. At the same time, the carbon penalty on natural gas is relatively smaller than on coal because of the lower carbon content of natural gas. Under certain relative prices, in the sectors where coal and natural gas can be used as a fuel interchangeably (e.g., in electricity generation) this can lead to a substitution from coal to natural gas use. However, in the case of China the relative fuel prices and carbon prices resulting from the cap-and-trade scheme do not lead to an increase in natural gas use. Without additional adjustments, this policy would create a substantive deviation from China's natural gas promotion objective.

The substitution of natural gas for coal has been treated as an important way to reduce local and regional air pollutions and to improve living standards in China. As the price of natural gas is higher than that of coal, a widespread switch from coal to gas may require a subsidy. Given China's primary energy consumption, a \$5 billion subsidy would be needed to achieve a $10 \%$ of natural gas contribution in 2020 . This may not be viable unless the government has a new revenue source. Carbon taxes or revenue from the sale of emission permits may provide such a source.

In the integrated policy scheme proposed and simulated in this study, part of the carbon revenue from the $\mathrm{CO}_{2}$ cap is used to subsidize natural gas consumption. In this way, both the climate objective and the natural gas promotion objective can be achieved. The integrated policy reduces the relative price of natural gas use for consumers and increases the cost of coal use, promoting the substitution of natural gas for coal while still meeting the climate policy objective. Compared to the cap-and-trade 
only case, there is a modest $(0.5 \%)$ welfare loss in 2030 associated with the integrated policy approach; however, it leads to a further reduction in $\mathrm{NO}_{x}$ emissions by $2.3 \%$ and $\mathrm{SO}_{2}$ emissions by $2.6 \%$ in 2030 .

As the integrated policy scheme results in a substantial increase in a use of natural gas in power and heat generation, and these generation units are mostly located in the most-populated Eastern areas of China, then, most likely, the effects of air pollution reduction would be more substantial in these areas. An assessment of the geographic distribution of air pollution and the resulting health impacts requires more spatially resolved tools. Further research calls for a broader integrated assessment framework consisting of an atmospheric chemistry model and an energy and economic model with health effects. The economy-wide model used in our study is a useful tool, as policymakers should be aware of the challenges in meeting the stated (and sometimes contradictory) objectives and inter-linkages of the actions towards the energy sector.

\section{Acknowledgments}

The authors are thankful to Jamie Bartholomay, Elena Kalinina and two anonymous reviewers for their valuable contributions. The Joint Program on the Science and Policy of Global Change is funded by a consortium of Federal awards and industrial and foundation sponsors (for the complete list see: http://globalchange.mit.edu/sponsors/all). Support from the U.S. Federal Government in the past three years was received from the U.S. Department of Energy, Office of Science under grants DEFG02-94ER61937, DE-SC0007114, DE-FG02-08ER64597; the U.S. Department of Energy, Oak Ridge National Laboratory under subcontract 4000109855; the U.S. Department of Agriculture under grant 58-6000-2-0099; the U.S. Energy Information Administration under grant DE-EI0001908; the U.S. Environmental Protection Agency under grants XA-83505101-0, XA-83600001-1, and RD-83427901-0; the U.S. Federal Aviation Administration under agreement 09-C-NE-MIT; the U.S. National Aeronautics and Space Administration under grants NNX13AH91A, NNX11AN72G, and sub-awards 4103-60255 and 4103-30368; the U.S. National Renewable Energy Laboratory under grant UGA-0-41029-15; the U.S. National Science Foundation under grants OCE-1434007, IIS-1028163, EF-1137306, AGS1216707, ARC-1203526, AGS-1339264, AGS-0944121, and sub-awards UTA08.950 and 1211086Z1; the U.S. Department of Transportation under grant DTRT57-10-C10015; and the U.S. Department of Commerce, National Oceanic and Atmospheric Administration under grant NA13OAR4310084.

\section{References}

BJX News (2015). Grid-connected solar capacity operated by State Grid Corporation of China reaches $32.8 \mathrm{GW}$ by October 2015. BJX.com. Available at: http://guangfu.bjx.com.cn/news/ 20151124/684447.shtml.

BP (2014). Statistical Review of world Energy 2014. BP plc, London, UK. 
BP (2015). Statistical Review of world Energy 2015. BP plc, London, UK.

Cai, H, M Wang, A Elgowainy and J Han (2012). Updated greenhouse gas and criteria air pollutant emission factors and their probability distribution functions for electric generating units. Argonne National Laboratory ANL/ESD/12-2.

China Electricity Council (CEC) (2015). Power industry profiles of China in 2014. CEC website. Available at: http://www.cec.org.cn/guihuayutongji/gongxufenxi/dianliyunxingjiankuang/2015-12-17/146909.html.

Chai, Q and X Zhang (2010). Technologies and policies for the transition to a sustainable energy system in China. Energy, 35(10), 3995-4002.

Chen, H, S Paltsev, J Reilly, J Morris and M Babiker (2015). The MIT EPPA6 model: Economic growth, energy use, and food consumption. MIT Joint Program on the Science and Policy of Global Change Report 278. Available at: http://globalchange.mit.edu/files/document/MITJPSPGC_Rpt278.pdf.

Chen, J and G Chen (2012). Analysis on operation cost of 9F gas-steam combined cycle power plants in power plants in Jiangsu province. Electric Power Construction, 33(8), 99-102.

Chen, Y, A Ebenstein, M Greenstone and H Li (2013). Evidence on the impact of sustained exposure to air pollution on life expectancy from China's Huai River Policy. Proceedings of the National Academy of Sciences United States of America, 110(32), 12936-12941.

China National Renewable Energy Centre (CNREC) (2015). Renewable Energy 2015. Available at: http://www.cnrec.org.cn/cbw/zh/2015-10-23-488.html.

CQCOAL News (2015). Bohai-rim steam-coal price drops to lowest point. CQCOAL.COM. Available at: http://news.cqcoal.com:9080/a/xinwenzixun/benwangkuaixun/2015/0930/ 58335.html.

Davidson, M, D Zhang, W Xiong, X Zhang and V Karplus (2016). Modelling the potential for wind energy integration on China's coal-heavy electricity grid. Nature Energy, 1, 16086.

U.S. Energy Information Administration (EIA) (1999). Natural gas 1998: Issues and trends. Available at: http://www.eia.gov/pub/oil_gas/natural_gas/analysis_publications/natural_ gas_1998_issues_trends/pdf/it98.pdf.

U.S. Energy Information Administration (EIA) (2010). Annual energy outlook 2010 early release.

Environmental Protection Agency (EPA) (1995). Compilation of air pollutant emission factors. Available at: https://www3.epa.gov/ttn/chief/ap42/index.html.

Environmental Protection Agency (EPA) (2014). Air quality index: A guide to air quality and your health. U.S. EPA Report EPA-456/F-14-002.

Environmental Protection Agency (EPA) (2015). The social cost of carbon. EPA fact sheet. Available at: https://www3.epa.gov/climatechange/Downloads/EPAactivities/social-costcarbon.pdf.

He, K, H Huo and Q Zhang (2002). Urban air pollution in China: Current status, characteristics, and progress. Annual Review of Energy and the Environment, 27, 397-431.

HTAP (2013). Hemispheric Transport Air Pollution version 2 dataset, Joint Research Centre, European Commission. Available at: http://edgar.jrc.ec.europa.eu/htap_v2/index.php? SECURE $=123$.

Huang, J, X Wang and T Xu (2008). Economic evaluation and influence factors analysis on biomass combustion for power generation. Renewable Energy Resources, 26(2), 95-99.

Huang, W (2012). Feasibility analysis of DB power plant. Master's thesis, South China University of Technology, China, Guangzhou.

Huo, Q, T Zhou, X Yang, J Li and Z Xiao (2015). Association analysis of economy and security of AP1000 nuclear power technology. Huadian Technology, 37(5), 1-3. 
International Energy Agency (IEA) (2012). World energy outlook. IEA/OECD, Paris, France. International Energy Agency (IEA) (2015). Special data release with revisions for People's Republic of China, IEA official website Available at: http://www.iea.org/publications/freepublications/publication/SpecialdatareleasewithrevisionsforPeoplesRepublicofChina04.11. 2015.pdf.

International Monetary Fund (IMF) (2015). World economic outlook database.

Kan, H, R Chen and S Tong (2012). Ambient air pollution, climate change, and population health in China. Environment International, 42, 10-19.

Lan, L (2014). Analysis of characteristics and economic for new energy power generation. PhD thesis, North China Electric Power University, China, Beijing.

$\mathrm{Li}, \mathrm{P}$ (2012). The $\mathrm{CO}_{2}$ emission control based on IGCC system and economic evaluation research. Master's thesis, North China Electric Power University, China, Beijing.

Li, Y (2010). Analysis of economy characteristics and improvement ways for Chinese nuclear power. Nuclear Power Engineering, 31(3), 132-135.

Liao, J (2015). Energy consumption analysis and economic benefit evaluation of $\mathrm{CO}_{2}$ capture system of NGCC power plant. Master's thesis, Beijing Jiaotong University, China, Beijing.

Matus, K, K Nam, N Selin, L Lamsal, J Reilly and S Paltsev (2012). Health damages from air pollution in China. Global Environmental Change, 2, 55-66.

MIT Joint Program (2014). 2014 Energy and Climate Outlook. MIT Joint Program on the Science and Policy of Global Change, Cambridge, MA. Available at: http://globalchange. mit.edu/Outlook2014.

Ministry of Finance (MOF) (2007). Opinions on Subsidizing the Development and Utilization of Coal-Bed Methane, Ministry of Finance. Available at: http://jjs.mof.gov.cn/zhengwuxinxi/zhengcefagui/201110/t20111026_602044.html.

Ministry of Finance (MOF), General Administration of Customs of China (GACC) and Administration of Taxation (AOT) (2011). Notice on the Adjustment of the Import Value-Added Tax on Imported Natural Gas (2011-2020). Available at: http://www.chinatax.gov.cn/ n810341/n810765/n812156/n812474/c1186477/content.html.

Morris, J, J Reilly and H Chen (2014). Advanced technologies in energy-economy models for climate change assessment. MIT Joint Program on the Science and Policy of Global Change Report 272. Available at: http://globalchange.mit.edu/files/document/MITJPSPGC_Rpt272. pdf.

Nam, K-M, C Waugh, S Paltsev, J Reilly and V Karplus (2013). Carbon co-benefits of tighter SO2 and NOx regulations in China. Global Environmental Change, 23(6), 1648-1661.

Nam, K-M, C Waugh, S Paltsev, J Reilly and V Karplus (2014). Synergy between pollution and carbon emissions control: Comparing China and the United States. Energy Economics, 46, 186-201.

Narayanan, B, A Aguiar and R McDougall (2012). Global Trade, Assistance, and Production: The GTAP 8 Data Base. Purdue University: Center for Global Trade Analysis.

National Bureau of Statistics of the People's Republic of China (NBS) (2014). China Energy Statistical Yearbook 2013. Beijing: NBS.

National Bureau of Statistics of the People's Republic of China (NBS) (2015a). China Energy Statistical Yearbook 2014. Beijing: NBS.

National Bureau of Statistics of the People's Republic of China (NBS) (2015b). Online Database. Available at: http://data.stats.gov.cn/easyquery.htm?cn=C01.

National Development and Reform Commission of China (NDRC) (2012). Revised natural gas utilization policy. Available at: http://www.sdpc.gov.cn/zcfb/zcfbl/201210/t20121031 511891.html. 
National Development and Reform Commission of China (NDRC) (2014). Notice of the national development and reform commission on regulating on-grid tariffs of natural gasfired power plants. Available at: http://www.sdpc.gov.cn/gzdt/201501/t20150114_660178. html.

National Development and Reform Commission of China (NDRC) (2015). Enhanced actions on climate change: China's intended nationally determined contributions. UNFCCC website. Available at: http://www4.unfccc.int/submissions/INDC/Published Documents/China/ 1/China's INDC — on 30 June 2015.pdf.

National Energy Agency of China (NEA) (2014). Costs of electricity generation project 20112012. Available at: http://www.nea.gov.cn/2014-05/30/c_133372232.htm.

National Energy Agency of China (NEA) (2015). National energy agency: Reviews of China's energy market for the first half of year 2015. NEA website. Available at: http://www.nea.gov. cn/2015-07/27/c_134450600.htm.

Natural Resources Defense Council (NRDC) (2015). From Copenhagen accord to climate action: Tracking national commitments to curb global warming. NRDC website. Available at: http://www.nrdc.org/international/copenhagenaccords/.

Octaviano, C, S Paltsev and A Gurgel (2016). Climate change policy in Brazil and Mexico: Results from the MIT EPPA model. Energy Economics, 56, 600-614.

Paltsev, S, J Reilly, H Jacoby, R Eckaus, J McFarland and M Babiker (2005). The MIT emissions prediction and policy analysis (EPPA) model: Version 4. MIT Joint Program on the Science and Policy of Global Change Report 125, p. 72. Available at: http://globalchange.mit.edu/files/document/MITJPSPGC_Rpt125.pdf.

Paltsev, S and D Zhang (2015a). Natural gas pricing reform in China: Getting closer to a market system? Energy Policy, 86, 43-56.

Paltsev, S and D Zhang (2015b). The future of nuclear power in China: Long-term scenarios, global 2015. 21st International Conference: Nuclear Fuel Cycle for a Low-Carbon Future, Paris, France, Available at: https://www.conftool.pro/global2015papers/index.php?page=browse Sessions\&form_session=1.

Paltsev, S and P Capros (2013). Cost concepts for climate change mitigation. Climate Change Economics, 4, 1340003-1340028.

Paltsev, S, J Morris, Y Cai, VJ Karplus and H Jacoby (2012). The role of China in mitigating climate change. Energy Economics, 34, S444-S450.

Reilly, J, S Paltsev, E Monier, H Chen, A Sokolov, J Huang, Q Ejaz, J Scott, J Morris and A Schlosser (2015). Energy \& Climate Outlook: Perspective from 2015. MIT Joint Program on the Science and Policy of Global Change. Available at: http://globalchange.mit.edu/ Outlook2015.

Rohde, R and M Muller (2015). Air pollution in China: Mapping of concentration and sources. PLOS ONE, 10(8), e0135749.

State Grid Corporation of China (SGCC) (2015). China's installed nuclear capacity will reach $30 \mathrm{GW}$ by the end of 2015. SGCC website. Available at: http://www.sgcc.com.cn/xwzx/ nyzx/2015/05/325945.shtml.

Shanghai Municipal Development and Reform Commission (SHDRC) (2015). Notice of the Shang municipal development and reform commission on adjusting natural gas price for non-residential users. Available at: http://www.shdrc.gov.cn/searchresult_detail.jsp?main _ artid $=26845 \&$ keyword $=\% \mathrm{CC} \% \mathrm{EC} \% \mathrm{C} 8 \% \mathrm{BB} \% \mathrm{C} 6 \% \mathrm{~F} 8$.

State Council of China (2013). $12^{\text {th }}$ five-year plan for energy development. Available at: http:// www.nea.gov.cn/2013-01/28/c_132132808.htm. 
State Council of China (2014). Energy development strategy action plan (2014-2020). Available at: http://www.gov.cn/zhengce/content/2014-11/19/content_9222.htm.

Sun, H and F Ning (2014). Introduction to gas-steam combined cycle. Urban Construction Theory Research, 22(4), 2014A4686 (in Mandarin).

The White House (2015). US-China joint presidential statement on climate change. Available at: https://www.whitehouse.gov/the-press-office/2015/09/25/us-china-joint-presidential-statement-climate-change.

Urumqi Customs District of China (2011). Gas import increases in volume and price at Xinjiang port during the first ten months of 2011. Urumqi Customs Website. Available at: http:// www.customs.gov.cn/publish/portal166/tab61950/info342624.htm.

Urumqi Customs District of China (2015). Gas import increases in volume but decreases in price at Xinjiang port during the first ten months of 2015. Urumqi Customs Website. Available at: http://www.customs.gov.cn/publish/portal166/tab61950/info778969.htm.

US Forex (2015). Historical exchange rates. Available at: http://www.usforex.com/forex-tools/ historical-rate-tools/yearly-average-rates.

Wang, Q and X Cheng (2015). Energy policies for managing China's carbon emission. Renewable and Sustainable Energy Reviews, 20, 470-479.

Xinhua News (2015). Energy officials say China is undertaking energy market reform during the 13th five-year plan period. Xinhuanet.com. Available at: http://news.xinhuanet.com/ fortune/2015-10/27/c_128364246.htm.

Yang, G, Y Wang, Y Zeng, G Gao, X Liang et al. (2013). Rapid health transition in China, 990-2010: Findings from the Global Burden of Disease Study 2010. Lancet, 381, 19872015.

Zhang, X, V Karplus, T Qi, D Zhang and J He (2016). Carbon emissions in China: How far can new efforts bend the curve? Energy Economics, 54, 388-395.

Zhou, Y, F Hao, W Meng and J Fu (2014). Scenario analysis of energy-based low-carbon development in China. Journal of Environmental Science, 26, 1631-1640. 